\title{
Warm sheet metal forming of energy-absorbing elements made 7075 aluminum alloy in the hardened state T6
}

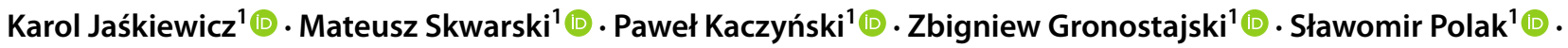 \\ Przemysław Trzpis ${ }^{2}$
}

Received: 20 September 2021 / Accepted: 8 December 2021 / Published online: 6 January 2022

(c) The Author(s) 2021

\begin{abstract}
The article covers experimental research on the forming of products made of 7075 aluminum alloy. This aluminum alloy grade is characterized by high strength, but due to its low formability in T6 temper, its use in the stamping processes of complex structural elements is limited. The authors have manufactured a U-shaped element at an elevated temperature and determined the optimal parameters of the process. Conventional heating of the sheet and shaping it at the temperature of 100 and $150^{\circ} \mathrm{C}$ allowed to obtain a product of high strength similar to the T6 state, above $540 \mathrm{MPa}$. Due to the excessive springback of the sheet during forming, these products were characterized by a large deviation of the shape geometry, exceeding the allowable values of $+/-1 \mathrm{~mm}$. Only the use of an alternative method of heating the sheet to temperatures of 200 and $240{ }^{\circ} \mathrm{C}$ (between plates at $350{ }^{\circ} \mathrm{C}$, heating time $2 \mathrm{~min}$, heating rate $1.8^{\circ} \mathrm{C} / \mathrm{s}$ ) allowed to obtain a product that meets both the strength and geometric requirements. The determined optimal process' parameters were later transferred to the stamping process of elements of a more complex shape (lower part of the B-pillar). The sheet was heated up and formed in the previously pre-heated tools. In the subsequent series of tests, the heating method and the blank's temperature were being analyzed. In the case of the foot of the B-pillar, it was necessary to lower the initial blank temperature to $200{ }^{\circ} \mathrm{C}$ (heating in a furnace with a temperature of $340^{\circ} \mathrm{C}$, heating speed $0.5^{\circ} \mathrm{C} / \mathrm{s}$ ). The appropriate combination of the process parameters resulted in the satisfactory shape deviation and reaching the product's strength comparable to the strength of the material in as-delivered T6 temper. Using electron microscopy, it was verified that the structure of the finished product contained particles $\mathrm{MgZn}_{2}$ that strongly strengthen the alloy. The obtained results complement the data on the possibility of using 7075 aluminum alloy to produce energy-absorbing elements of motor vehicles.
\end{abstract}

Keywords 7075 aluminum alloy $\cdot$ Warm stamping $\cdot$ B-pillar $\cdot$ Springback

Mateusz Skwarski

mateusz.skwarski@pwr.edu.pl

Karol Jaśkiewicz

karol.jaskiewicz@pwr.edu.pl

Paweł Kaczyński

pawel.kaczynski@pwr.edu.pl

Zbigniew Gronostajski

zbigniew.gronostajski@pwr.edu.pl

Sławomir Polak

slawomir.polak@pwr.edu.pl

Przemysław Trzpis

przemyslaw.trzpis@kirchhoff-automotive.com

1 Faculty of Mechanical Engineering, Wrocław University of Science and Technology, Wybrzeże Stanisława, Wyspiańskiego 27, 50-370 Wrocław, Poland

2 Kirchhoff Polska Sp.z.o.o, Wojska Polskiego 3, 39-300 Mielec, Poland

\section{Introduction}

The trend towards weight reduction, which is still present in the automotive industry, means that manufacturers strive to make the car body as light as possible while maintaining appropriate strength and stiffness to ensure the proper safety of car users. One way to reduce the weight is to replace steel elements with lighter, equally strong aluminum alloy parts [1]. The body of the Audi A8 is an excellent example of a structure almost entirely made of $5 \mathrm{xxx}$ and $6 \mathrm{xxx}$ series aluminum alloys [2,3]. However, some of the most crucial elements are still made of highstrength steel grades [4]. An excellent example of such a part is the B-pillar. Even cars made of aluminum alloys are equipped with B-pillars hot stamped from 22MnB5 manganese-boron steel. In many scientific centers, 
experimental research and numerical simulations are carried out to replace $22 \mathrm{MnB} 5$ steel with alloys of another group (e.g., the third generation of steels) [5]. Li et al. conducted research on the production of B-pillars made of the third-generation AHSS medium manganese steel grades. The strength properties, formability, microstructure, and crashworthiness of the final products were studied. Boron-alloyed steels have a wide range of hardening temperatures (from CCT curves), which is more advantageous for hot forming processes. Due to the even distribution of the fine-grained martensite, it was possible to form a B-pillar of superior energy absorption and higher strength (in comparison with 22MnB5 steel grade) [6].

The only materials among light metal alloys that can currently compete with $22 \mathrm{MnB} 5$ steel in terms of high strength are the $7 \mathrm{xxx}$ series of aluminum alloys. 7075 alloy, used since the 1970s, can be distinguished in this group. However, there is a significant difference between the strength of 7075 aluminum alloy and 22MnB5 steel (Fig. 1).

The automotive industry's desire to develop and manufacture an all-aluminum vehicle body is motivated by cost-effectiveness, environmental sustainability, and a pure marketing approach. The use of aluminum alloys is motivated by their high specific strength (strength related to the density of the material). Its use allows reducing the vehicle's weight, which results in lower fuel consumption and exhaust gas emissions. Furthermore, an all-aluminum car body would allow eliminating the problem of connecting different materials. Steel elements such as the B-pillar can be joined with the rest of the aluminum body utilizing adhesives, but it causes many technological complications. Sadowski et al. conducted experimental research on the behavior of the bonded thin-walled " $\Omega$ "-shaped elements in the entire load range [7]. The results in the form of force-displacement curves allowed the determination of maximum and residual force. The developed model for energy absorption showed very high compliance with the experimental results for two modes of deformation. Wojdat et al. [8] presented a numerical and mathematical approach to welding 7075 aluminum alloy. The welding is possible on the condition that the optimum welding parameters are determined beforehand, which may be very expensive and time-consuming. In the case of 7075 alloys, a high-strength weld $(R e=120 \mathrm{MPa})$ without defects may be obtained using gas-shielded arc welding (GMAW) with a fusible electrode welding technology. The team of Kubit [9] tested another approach to joining 7075 aluminum alloy. The authors determined the influence of refill friction stir spot welding (RFSSW) method parameters on the strength of the resulting joints. Based on shear tests, the optimal rotational velocity of the tool, tool depth, and joining time was established. During shear tests, three main breaking modes were observed: plug-type fracture, plug-shear fracture, and shear fracture.

The body parts of the vehicle form a so-called safety cage. Therefore each element must meet strict strength criteria. The 3-mm-thick sheet made of T6 temper 7075 aluminum alloy can be used to manufacture car body elements of a strength comparable to 1.8 -mm-thick UHSS elements. However, due to the complex geometry of the product and the alloy's low formability, cold forming of the T6 temper sheets is practically impossible. Therefore, this research aims to develop a stamping technology of 7075 aluminum alloy.

Krajewski [10] patented the method for stamping agehardenable aluminum alloy sheets at an ambient temperature called supersaturated forming. This technology has been extensively studied by Argandoña et al. [11]. The approach is based on heating the aluminum alloy above the liquidus temperature (about $500{ }^{\circ} \mathrm{C}$ ) for about an hour.
Fig. 1 Comparison of stressstrain curves of 7075 aluminum alloy and 22MnB5 steel (authors' tests)

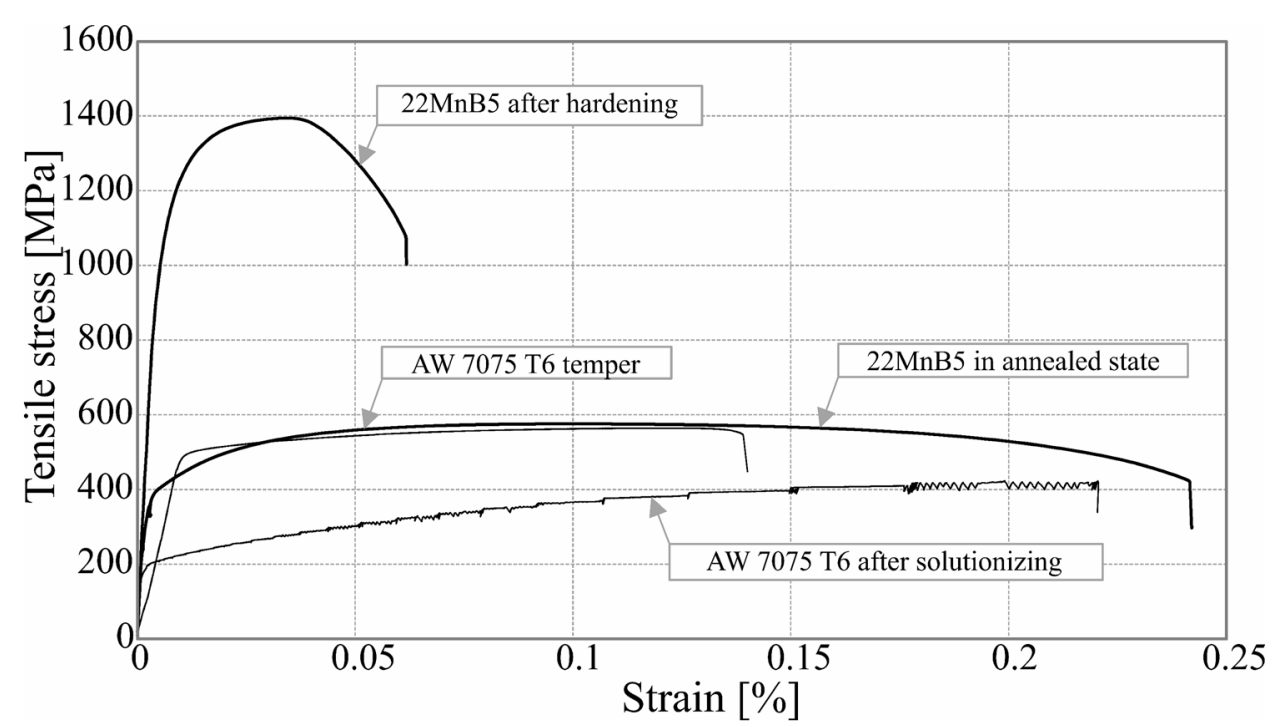


It dissolves all the phases and precipitates in the material's microstructure. In the next step, the material is cooled to ambient temperature at an appropriate rate. The supersaturated material exhibits good formability, but this state is volatile and changes dynamically in a short time. After the solutioning process, the material spontaneously ages (strengthens) over time, even a few weeks. Therefore, it is challenging to provide repeatable quality of the products made of supersaturated material. In addition, to regain their original strength, the products need to undergo further heat treatment such as artificial aging, carried out above $100{ }^{\circ} \mathrm{C}$ for a specific time.

Another way of forming a finished product made of 7075 aluminum alloy is called warm forming. It was widely described by Mahabunphachai and Koç [12]. It consists in forming at an elevated temperature, which involves preheating the input material and press forming using hot tools. As the material is heated, the yield strength decreases and the grain size changes, affecting the final strength due to thermally activated displacement of the dislocation lines. Wang et al. performed limiting drawing ratio and limiting dome height tests for 7075 aluminum alloy. It turned out that the temperature at which the material acquires formability without losing its strength is in the range below the recrystallization temperature (about $140-260^{\circ} \mathrm{C}$ ) [13]. The reason for increased formability is a decrease in the dislocation density and polygonization of the dislocation. Heating the material to temperatures above $260{ }^{\circ} \mathrm{C}$ causes permanent microstructural changes, reducing the final product's mechanical properties. It should also be noted that the elevated temperature increases the material's strain rate sensitivity and the friction coefficient between the sheet and the tools [14]. The study on the 7000 series alloys carried out by Kumar et al. shows that the most favorable forming temperature is $250{ }^{\circ} \mathrm{C}$ as it dissolves the metastable precipitations, which are responsible for high strength and low formability [15]. Moreover, the artificial aging of the hot-stamped finished product during the paint baking restores the hardness to the initial value (hardness of T6 temper). Polak et al. have warm stamped car brackets using 7075 aluminum alloy. The final product had a complex geometry and was free from defects and cracks, but the strength was slightly decreased [16]. Deng et al. and Wang et al. described that the geometry of warm-formed elements might not fall within the acceptable range of shape deviations $[17,18]$. This is caused by the strong springback of the material. The authors report that the springback may be reduced by $10 \%$ if the blanks are formed under isothermal conditions. Moreover, the increased deformation rate results in lower dynamic recovery and increased dimensional stability. The higher the rate of deformation, the more favorable the forming conditions are due to the lower dynamic recovery, which increases the deformation and springback stability. In warm forming processes, where both the workpiece material and the forming tools have an elevated temperature, not necessarily the same value, a very important aspect when analyzing and considering such cases is the heat conduction coefficient and heat transfer coefficient $[19,20]$. Chen et al. [21] report that heating the surface of the punch and die to a higher temperature than the core temperature increases the formability of the aluminum alloy. The result was obtained with the FEM modeling of warm forming processes.

The third forming method of hard-deformable aluminum alloys is hot forming, which was patented by Foster et al. [22]. The blank is held at $500{ }^{\circ} \mathrm{C}$ for the time necessary to fully dissolve the precipitates and reinforcing phases in the material's structure. In such a state, the material is highly formable, which allows obtaining a complex geometry. Therefore, the hot sheet should be transferred to the cold tools and immediately stamped. Teams of Mackenzie (Mackenzie and Nwekirk 2001) and Mattos (Mattos et al. 2016) described that using high pressure allows transferring the heat from the blank to the tools so quickly that the material becomes saturated at ambient temperature [23, 24]. Xiao et al. and $\mathrm{Hu}$ et al. have proved that the supersaturated state is necessary for further heat treatment such as artificial aging. During this process, releasing the particles and strongly strengthening phases (such as $\mathrm{MgZn}_{2}$ ) occur, restoring very high strength and hardness properties [25, 26]. One of the ideas to increase the plasticity of the material during forming is the hot stamping process with pre-cooling. Pre-cooling stage between solutioning and forming causes increase in the strain hardening exponent of material. For the pre-cooling temperature $300{ }^{\circ} \mathrm{C}$, the formed parts had the smallest thickness thinning and less precipitation during quenching, which ensured good subsequent aging strengthening effect [27].

In the scientific and industrial environments, it has not been possible to manufacture car body elements made of light alloys that would meet all of the geometry, surface quality, strength, energy absorption, and safety requirements [28]. Based on the authors' market research, there is a deep need to develop a technology for producing components made of high-strength aluminum alloys. The developed manufacturing technology of the U-shaped element and the lower part of the car's B-pillar can be easily adapted to the actual industrial conditions. It will allow for the production of other car body elements, such as door reinforcements, sills, frame side members, and roof elements. The authors' attempts to stamp a 3-mm-thick 
Table 1 Chemical composition of 7075 aluminum alloy in the T6 temper

\begin{tabular}{lllllllllll}
\hline Element & $\mathrm{Si}$ & $\mathrm{Fe}$ & $\mathrm{Cu}$ & $\mathrm{Mn}$ & $\mathrm{Mg}$ & $\mathrm{Cr}$ & $\mathrm{Zn}$ & $\mathrm{Ti}$ & $\mathrm{Ti}+\mathrm{Zr}$ & $\mathrm{Others}$ \\
\hline $\begin{array}{l}\text { Acceptable content } \\
{[\%]}\end{array}$ & $0-0.4$ & $0-0.5$ & $1.2-2.0$ & $0-0.3$ & $2.1-2.9$ & $0.18-0.28$ & $5.1-6.1$ & $0-0.2$ & $0-0.25$ & $0-0.05$ \\
$\begin{array}{l}\text { Real content } \\
{[\%]}\end{array}$ & 0.06 & 0.12 & 1.6 & 0.02 & 2.6 & 0.19 & 5.8 & 0.05 & 0.08 & 0.02 \\
\hline
\end{tabular}

sheet made of T6 temper 7075 aluminum alloy at room temperature resulted in material cracking. The efforts of scientists from Spain [11] and China [29] also came to nothing. Cold stamping the 7000 series aluminum alloys will always result in material cracking and folding, regardless of whether lubricant is used.

The current study was proposed to successfully stamp T6 temper 7075 aluminum alloy at an elevated temperature and identify the forming parameters that would allow reaching a compromise between forming accuracy, postforming properties, and formability of complex shapes.

\section{Material and methods}

\subsection{Material}

The U-shaped elements and the bottom part of the B-pillar were formed using 3-mm-thick 7075 aluminum alloy in the as-delivered $\mathrm{T} 6$ temper. The chemical composition of the alloy is shown in Table 1. Table 2 depicts the basic mechanical properties of the T6 temper 7075 according to tests conducted by the authors.

The dog-bone specimens (Fig. 2) were cut out from a sheet. The tensile tests were performed according to the PN-EN ISO 6892-1 using 147,800/01 Zwick Roell universal testing machine with a measuring range of $0-100 \mathrm{kN}$.

Tensile tests were carried out for constant strain rates of $10^{-3}, 10^{-2}$, and $10^{-1} \mathrm{~s}^{-1}$ in temperatures ranging from 100 to $300{ }^{\circ} \mathrm{C}$. The specimens were held at a given temperature for 15 min (after reaching the desired temperature) and subsequently tested until rupture. Conducted tensile tests allowed to determine the temperature and strain rate influence on the plasticizing stress and the material's formability. The temperature range at which

Table 2 Mechanical properties of the material in the T6 temper

\begin{tabular}{lllll}
\hline Temper & $\begin{array}{l}\text { Ultimate tensile } \\
\text { strength }[\mathrm{MPa}]\end{array}$ & $\begin{array}{l}\text { Yield strength } \\
{[\mathrm{MPa}]}\end{array}$ & $\begin{array}{l}\text { Maximum } \\
\text { elongation } \\
{[\%]}\end{array}$ & $\begin{array}{l}\text { Hardness } \\
{[\mathrm{HV} 1]}\end{array}$ \\
\hline T6 & $580-590$ & $518-520$ & $11-12$ & $190-196$ \\
\hline
\end{tabular}

T6 temper 7075 aluminum alloy can be formed to obtain complex shapes while maintaining high-strength properties was specified.

\subsection{Manufacturing components and tools detail}

For structural reasons, the geometry of the B-pillar is complex. For the research purposes, three main zones of varying technological complexity were distinguished (Fig. 3). Zone I (central part) is characterized by the most straightforward geometry, in which mostly bending occurs and plane state of strain can be assumed (biaxial). Separated zone II (B-pillar's head) and zone III (B-pillar's foot), located at both ends of the B-pillar, are geometrically similar to each other. At first, a series of experimental tests consisting in the bending of a U-shaped element (Fig. 4a) with a flange was conducted. To some extent, it resembles the central part of the B-pillar (Fig. 3). In order to verify the determined parameters of the process, B-pillar's foot (Fig. 4b) was stamped using the same parameters. The transition from the established bending conditions to the stamping of the B-pillar's foot (zone III) requires adjusting the process parameters. This methodology allows to shorten the technology development time and reduce the costeffectiveness of the process.

The stamping tests of U-shaped elements were carried out on a test stand (Fig. 5a) located in the Department of Metal Forming, Welding, and Metrology of the Wroclaw University of Science and Technology. The forming tools (Fig. 5a) were designed and manufactured by Kirchhoff, Poland, located in Mielec. The stamping die was made of improved $1.2738 \mathrm{HHH}$ steel characterized by very low thermal expansion and high thermal stability. A specialist heating system was used to facilitate temperature regulation. It consisted of cartridge heaters installed in the tool's core and K-type thermocouples (Fig. 5b).

The stamping of the B-pillar's foot was carried out on the test stand depicted in Fig. 6a, b. The stamping die was made of improved $1.2738 \mathrm{HHH}$ steel (like the tools for U-shaped element stamping) characterized by very low thermal expansion and high thermal stability. 
Fig. 2 Detailed drawing of the dog-bone specimen

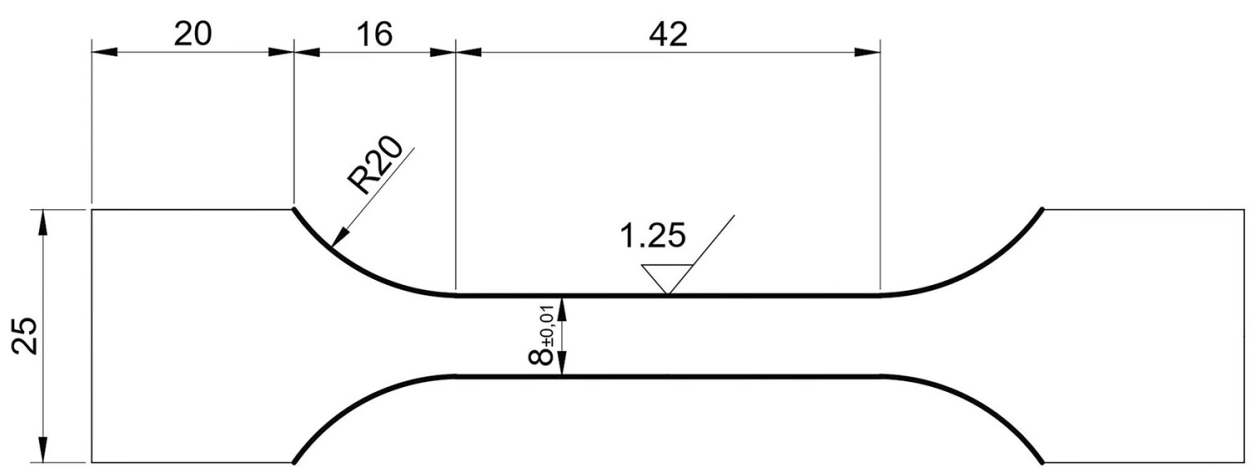

\subsection{Blank preheating strategy}

Based on previous authors' studies, it was observed that heating of 7075-T6 aluminum alloy sheets results in a significant deformability increase and hardness decrease [16]. Therefore, preliminary tests were conducted, including changing the holding time and temperature. In order to eliminate the material deformation, the tests were conducted using $30 \times 20 \mathrm{~mm}$ rectangular specimens cut out from 3-mm-thick 7075 aluminum alloy sheets. In order to minimize heating time, the process was carried out between two plates pre-heated to the temperatures of 150 , 200 , and $240{ }^{\circ} \mathrm{C}$. After reaching the desired temperature, the specimens were additionally held for a period of time from 0 to $60 \mathrm{~min}$.

In the next step, full-scale blanks were used, and three different heating strategies were tested to manufacture both a U-shaped element and B-pillar's foot. The first strategy was free heating in the furnace pre-heated to $240{ }^{\circ} \mathrm{C}$. The blank was removed from the furnace after reaching $100,150,200$, and $240{ }^{\circ} \mathrm{C}\left( \pm 5^{\circ} \mathrm{C}\right)$ and immediately bent (U-shaped). An additional reference test was conducted using the blank of ambient temperature $\left(21^{\circ} \mathrm{C}\right)$. The temperature of the forming tools was equal to $220{ }^{\circ} \mathrm{C}\left( \pm 5^{\circ} \mathrm{C}\right)$. Five tests were carried out for each of the specified conditions. The punch velocity was

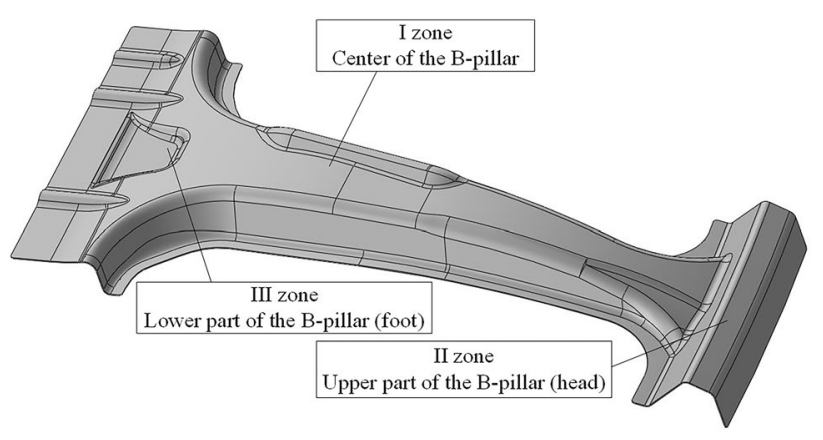

Fig. 3 Model of the B-pillar
$10 \mathrm{~mm} / \mathrm{s}$, and the maximum stamping force was set to $1600 \mathrm{kN}$. The second strategy was to raise the furnace temperature to $350{ }^{\circ} \mathrm{C}$. The heating of the sheet at an elevated temperature resulted in a reduction of the heating time (the shorter the heating time of the material, the fewer structural changes occur). The third strategy (heating between plates) was to replace the conventional furnace with conductive heating by means of two steel plates, which had been pre-heated to $350{ }^{\circ} \mathrm{C}$. When the desired temperature was reached, the plates were moved away, and the heating was stopped. Other operations such as immediate transfer of the hot blank to the hot tools and all process parameters such as tools temperature and the punch velocity remained unchanged. The use of three different heating methods allowed authors to test three different heating rates and to examine their impact on the strength properties and geometry of the finished product. The test parameters are presented in Table 3 .

In order to monitor the temperature changes, four holes (diameter of $\phi 1.2 \mathrm{~mm}$ ) were drilled in the symmetry plane of the blank to a depth of $15 \mathrm{~mm}$. Next, the K-type thermocouples were mounted inside the holes (Fig. 7) and connected to a measuring system.

For technological reasons, only the first and second heating strategies were used when stamping B-pillar's foot (the blank was always heated up in the resistance furnace, which was pre-heated to $240{ }^{\circ} \mathrm{C}$ or $350{ }^{\circ} \mathrm{C}$ in order to reduce the heating time). Due to the large surface area of the blank, its heating between the plates would cause too much shrinkage and bending, so heat dissipation from the material would be uneven. It is worth mentioning that there were no stops between the tool's approach and the stamping (similar to the U-shaped element stamping). In order to verify the heating time, K-type thermocouples were installed (Fig. 8). The process parameters remained unchanged. Additionally, due to the complex shape of the B-pillar's foot, the lubricating agent was used. Paraffin oil, recommended for the hot stamping of aluminum alloys, was applied directly on the surface of the shaping tools. 
$\mathbf{a}$
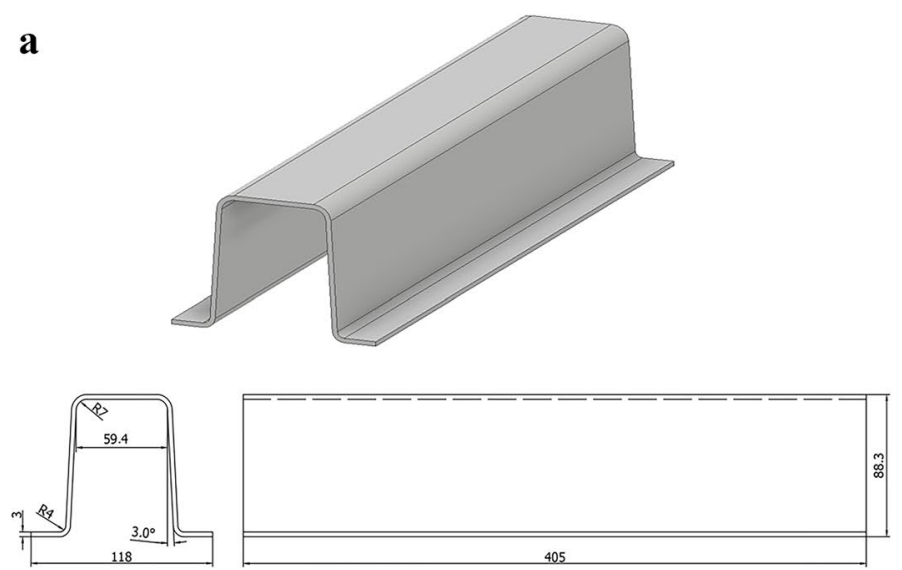

b

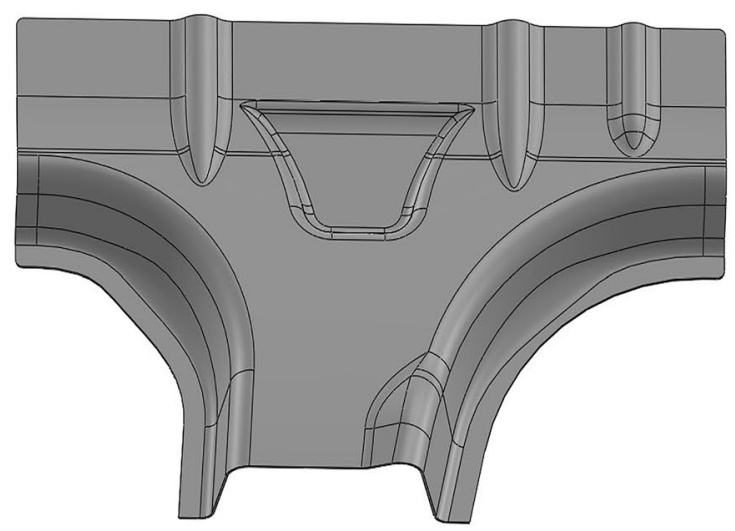

Fig. 4 Model of manufactured elements (a) U-shaped element, (b) the B-pillar's foot

\subsection{Tested components}

Finished products (U-shape and the B-pillar's foot) were subjected to quality tests. In particular, these are laboratory tests applied by the manufacturer, which allow qualifying the drawpiece as correct. The tests include dimensional stability and shape verification, hardness, strength, and microstructure tests.

\subsubsection{Measurement of shape deviations}

After the bending test, each drawpiece was scanned using a 7520si ROMER absolute measuring arm equipped with an integrated RS3 contactless scanner. The device precision is within the range of $\pm 0.03 \mathrm{~mm}$. The scanned points were compared with the nominal 3D model. As a result, shape deviations were determined. In the case of the U-shape, the geometry deviations for the 13 points (Fig. 9b) lying on the symmetry plane (in Fig. 9a) were determined. In the case of the B-pillar's foot, the deviation was determined for 23 surface points ( Fig. 10).

Measurement of the obtained product's geometry serves as a criterion to evaluate developed manufacturing technology. The criterion for products of this type used in industrial practice equals to $\pm 1 \mathrm{~mm}$.

\subsubsection{Hardness measurement}

After the forming process, rectangular specimens were cut out from the U-shape and the B-pillar's foot for hardness testing. The measurements were conducted according to the PN-EN ISO 6507-1:2007 standard, using a LECO hardness tester (HV1 scale). A pyramid-shaped indenter was pressed into the cleaned and polished surface with a force of $1000 \mathrm{~g}$. The crucial locations shown in Fig. 11 were selected for the measurement. In each of the tested locations, 5 indentations were made (at a minimum distance of $0.2 \mathrm{~mm}$ from each other), and the mean value was calculated.

There is a strong correlation between the hardness and strength of the tested material. The hardness measurement will verify the results obtained during the strength tests. In addition, it will allow to determine the influence of the thermoplastic treatment on the strengthening precipitates of the material.

\subsubsection{Strength test}

Dog-bone tensile specimens were cut out from the locations marked in Fig. 12. Their shape was compliant with Fig. 3.
Fig. 5 The U-shaped elements stamping station (a) view of the stand, (b) shape and dimensions of the forming tools
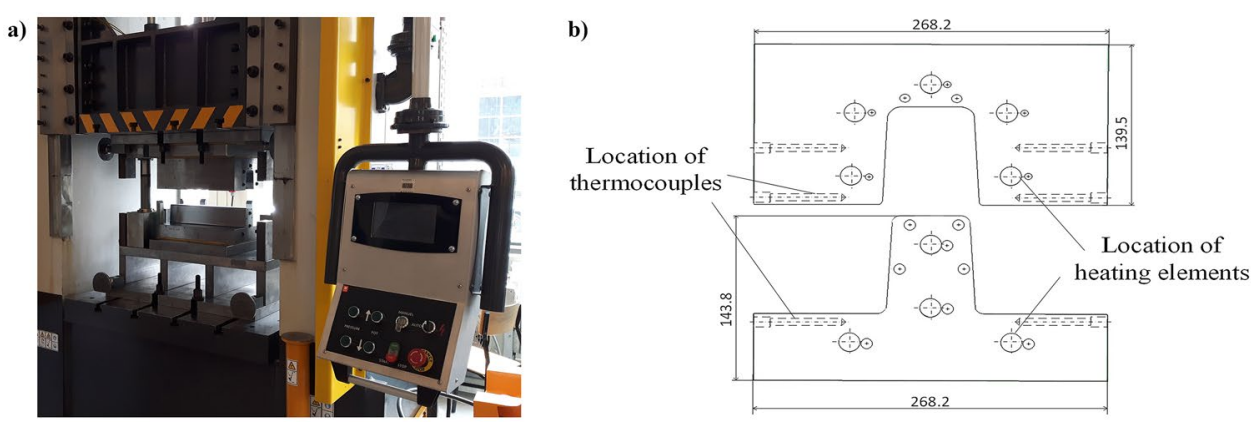
a)

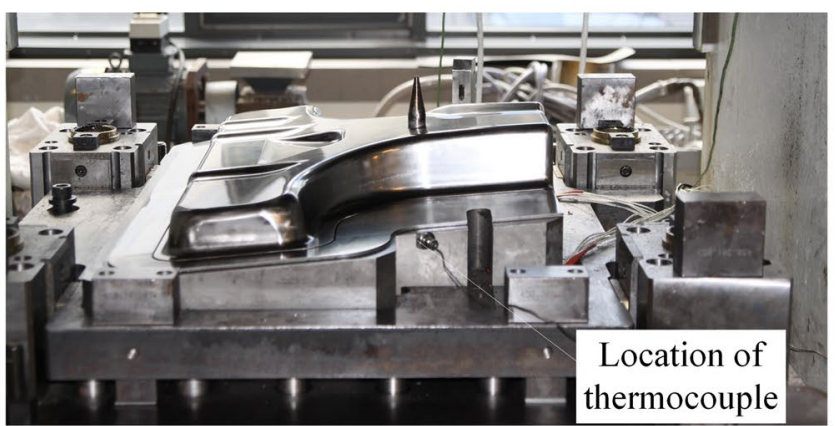

b)

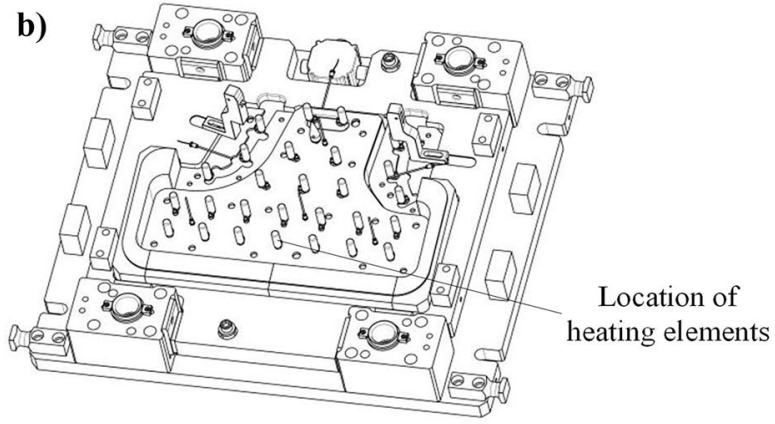

Fig. 6 The B-pillar's foot stamping station (a) view of the stand, (b) shape and dimensions of the forming tools

The tensile tests were carried out on a Zwick universal testing machine.

Static tensile testing is a criterion for evaluating if the finished product can be used for automotive body parts. The strength of different locations will determine if the supersaturated areas regained T6 temper strength.

\subsubsection{Microstructure}

Specimens cut out from a T6 temper 7075 aluminum alloy sheet and a gripping part of the tensile specimen characterized by the highest strength were used for structural testing.

Before microscope testing, the specimens were grounded, polished, and etched with Mi1 $\mathrm{Al}$ reagent $\left(0.5 \mathrm{~cm}^{3} \mathrm{HF}+99.5\right.$ $\left.\mathrm{cm}^{3} \mathrm{H}_{2} \mathrm{O}\right)$. The microstructure analysis was done using GX51 Olympus optical microscope (to reveal and compare grain sizes) and Tecnai G20 transmission electron microscope (to reveal the types and sizes of precipitates).

\section{Results and discussion}

\subsection{Material}

The strength properties of T6 temper aluminum alloy in the temperature range from 21 to $300{ }^{\circ} \mathrm{C}$ are presented in Fig. 13.

According to the forming limit diagrams of the alloy available in the literature, forming without losing stability and strength is achieved at $200-250{ }^{\circ} \mathrm{C}$. This relation

Table 3 Research methodology

\begin{tabular}{llll}
\hline Preheating strategy & $\begin{array}{l}\text { The temperature of } \\
\text { the blank }\end{array}$ & $\begin{array}{l}\text { The temperature of } \\
\text { the tools }\end{array}$ & $\begin{array}{l}\text { Punch } \\
\text { movement } \\
\text { velocity }\end{array}$ \\
\hline 1st strategy (heating in the furnace $240{ }^{\circ} \mathrm{C}$ ) & $21{ }^{\circ} \mathrm{C}$ & $220{ }^{\circ} \mathrm{C}$ & $2 \mathrm{~mm} / \mathrm{s}^{*}$ \\
& $21{ }^{\circ} \mathrm{C}$ & $220{ }^{\circ} \mathrm{C}$ & $10 \mathrm{~mm} / \mathrm{s}$ \\
& $100{ }^{\circ} \mathrm{C}$ & $220{ }^{\circ} \mathrm{C}$ & $10 \mathrm{~mm} / \mathrm{s}$ \\
& $150{ }^{\circ} \mathrm{C}$ & $220{ }^{\circ} \mathrm{C}$ & $10 \mathrm{~mm} / \mathrm{s}$ \\
& $200{ }^{\circ} \mathrm{C}$ & $220{ }^{\circ} \mathrm{C}$ & $10 \mathrm{~mm} / \mathrm{s}$ \\
2nd strategy (heating in the furnace $\left.350{ }^{\circ} \mathrm{C}\right)$ & $240{ }^{\circ} \mathrm{C}$ & $220{ }^{\circ} \mathrm{C}$ & $10 \mathrm{~mm} / \mathrm{s}$ \\
& $150{ }^{\circ} \mathrm{C}^{* *}$ & $220{ }^{\circ} \mathrm{C}$ & $10 \mathrm{~mm} / \mathrm{s}$ \\
3rd strategy (heating between plates $\left.350{ }^{\circ} \mathrm{C}\right)$ & $200{ }^{\circ} \mathrm{C}$ & $220{ }^{\circ} \mathrm{C}$ & $10 \mathrm{~mm} / \mathrm{s}$ \\
& $240{ }^{\circ} \mathrm{C}$ & $220{ }^{\circ} \mathrm{C}$ & $10 \mathrm{~mm} / \mathrm{s}$ \\
& $150{ }^{\circ} \mathrm{C}$ & $220{ }^{\circ} \mathrm{C}$ & $10 \mathrm{~mm} / \mathrm{s}$ \\
& $200{ }^{\circ} \mathrm{C}$ & $220{ }^{\circ} \mathrm{C}$ & $10 \mathrm{~mm} / \mathrm{s}$ \\
& $240{ }^{\circ} \mathrm{C}$ & $220{ }^{\circ} \mathrm{C}$ & $10 \mathrm{~mm} / \mathrm{s}$ \\
\hline
\end{tabular}

*The specimen stamped out from cold $\left(21^{\circ} \mathrm{C}\right)$ blank by hot tools $\left(220^{\circ} \mathrm{C}\right)$ cracked in several places during the forming process. This behavior was probably caused by excessive forming speed and short contact time of the blank with the heated tools. The material did not manage to heat up to the temperature at which it would achieve sufficient formability. Therefore, the punch movement speed was reduced to $2 \mathrm{~mm} / \mathrm{s}$

**Because the material's strength at room temperature and heated up to $100{ }^{\circ} \mathrm{C}$ is almost identical, further tests were carried out only for the blanks heated up to 150,200 , and $240{ }^{\circ} \mathrm{C}\left( \pm 5^{\circ} \mathrm{C}\right)$ 


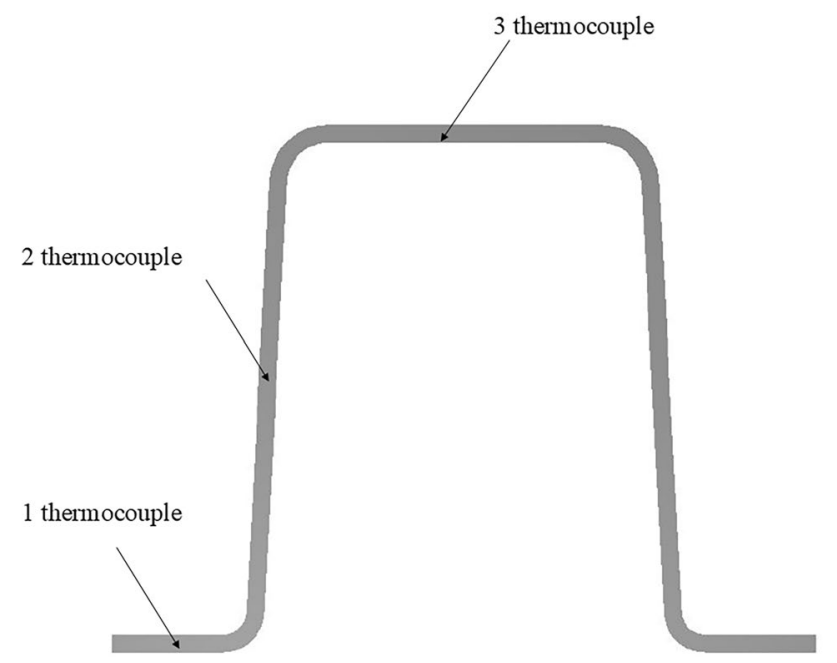

Fig. 7 Location of the thermocouples on the U-shaped element

was confirmed during tensile testing (Fig. 13). Increasing the deformation temperature to $200{ }^{\circ} \mathrm{C}$ resulted in an increase in the deformability from 12 to $22 \%$. The highest elongation of $30-40 \%$ was obtained at $300{ }^{\circ} \mathrm{C}$ (above the recrystallization temperature of aluminum alloy $\approx 270{ }^{\circ} \mathrm{C}$ ). However, any interference with the material's microstructure, including heat treatment, permanently changes the alloy's strength. The higher the temperature and the longer the heating time of the material, the lower its strength after cooling down. Forming blank at $300 \mathrm{C}$ is unfavorable because of the progressive remodeling of the microstructure, which causes a significant strength decrease. Reducing the forming temperature below $250{ }^{\circ} \mathrm{C}$ provides a sufficiently large plastic deformation without interfering with the material's structure.

In addition, from the obtained stress-strain curves, it was observed that the material is strain rate sensitive at elevated temperatures (as the strain rate increases, the level of plasticizing stress required for plastic deformation increases).

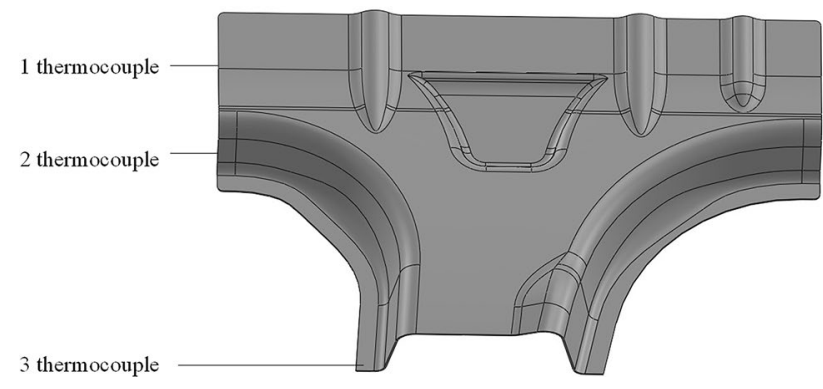

Fig. 8 Location of the thermocouples on the B-pillar's foot

\subsection{Blank preheating strategy}

Figure 14 depicts the dependence of the temperature and holding time on the hardness of the 7075 aluminum alloy. The reference point represents the sheet in the asdelivered T6 temper (approximately 195 HV1), while the holding time of $0 \mathrm{~s}$ represents the material's hardness measured immediately after reaching the desired temperature.

The presented data proved that at the temperature of $240{ }^{\circ} \mathrm{C}$, the hardness of the 7075 alloy drops rapidly after only 2 min after reaching the set temperature. After 5 min the hardness significantly drops to 125 HV1. Further holding causes the hardness reduction to approx $105 \mathrm{HV} 1$. Heating the alloy at the temperature of $200{ }^{\circ} \mathrm{C}$ results in maintaining decidedly higher strength parameters. After $60 \mathrm{~min}$ of heating, the minimum hardness was equal to $155 \mathrm{HV} 1$, while the reduction of holding time to 10 min allows retaining the hardness of about 170 HV1. The lowest hardness drop is observed in the case of holding the alloy at $150{ }^{\circ} \mathrm{C}$. After $60 \mathrm{~min}$ of heating, the alloy maintains its hardness at the level of $185 \mathrm{HV} 1$. However, at this temperature, the formability is very limited (Fig. 13). Although simple bending should not be a problem, stamping elements of complex shapes may be difficult or even impossible.

Figure 15 depicts the effect of different heating methods on the heating rate. The blank placed between the plates reached the desired temperature after only 1 to $2 \mathrm{~min}$. When heating it in a resistance furnace at $240{ }^{\circ} \mathrm{C}$, the preset temperature was reached after $35 \mathrm{~min}$, while increasing the furnace temperature to $350{ }^{\circ} \mathrm{C}$ shortened the heating time to $6 \mathrm{~min}$. Additionally, the sheet heating rate was determined using the presented diagrams.

Taking into account the hardness testing (Fig. 14) and the heating time measurement (Fig. 15), it can be concluded that the best forming temperature of the 7075 alloy is $150{ }^{\circ} \mathrm{C}$ (hardness value equals $190 \mathrm{HV} 1$, which is very close to the maximum hardness of the alloy in the T6 temper). The increase of temperature to $200{ }^{\circ} \mathrm{C}$ results in a hardness decrease by $10-20 \mathrm{HV} 1$ regardless of the heating time. In the case of both temperatures $\left(150{ }^{\circ} \mathrm{C}\right.$ and $200{ }^{\circ} \mathrm{C}$ ), the heating time of $10 \mathrm{~min}$ is the limit time, above which a considerable decrease in hardness occurs. Therefore the maximum heating time should be $10 \mathrm{~min}$. Based on Fig. 15, it can be concluded that the 2nd and 3rd heating strategies ensure that the target temperature is reached before $10 \mathrm{~min}$ (heating time for the 1st strategy is $38 \mathrm{~min}$, for the 2nd strategy $6.5 \mathrm{~min}$, and for the $3 \mathrm{rd}$ strategy $2 \mathrm{~min}$ ). 
a)

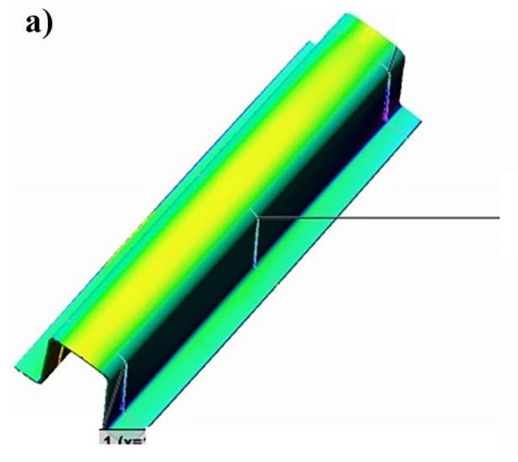

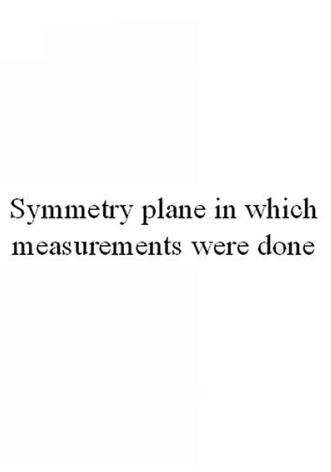

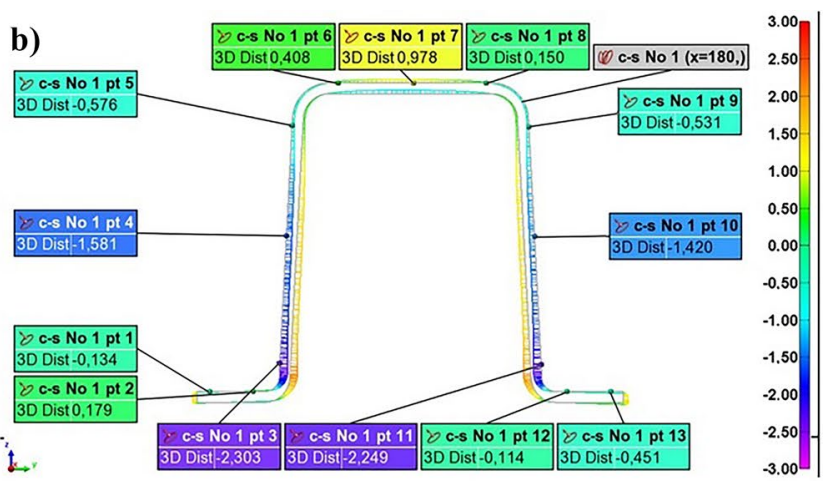

Fig. 9 The U-shape (a) measured cross-section, (b) points for which the shape deviations were determined

\subsection{Tested components - U-shape}

\subsubsection{Geometry}

The geometry deviation of the U-shaped elements produced according to the 1st strategy is shown in Fig. 16. The deviations of final products manufactured according to 2 nd and 3rd strategies are shown in Fig. 17.

In the case of the 1st strategy, the lowest shape deviations were obtained for the blank temperatures of 200 and $240{ }^{\circ} \mathrm{C}$ (Fig. 16). Lower temperatures result in significant springing and unacceptable shape deviations of the drawpiece.
Furthermore, the analysis of Figs. 16 and 17 allows concluding that the shape deviations in the area defined by points from 5 to 9 (Fig. 9b) do not significantly depend on the temperature of the blank. The most significant differences were observed in the flange areas defined by points 1 to 3 and 11 to 13 . The springing of the material causes excessive shape deviations of the blank preheated to 100 and $150^{\circ} \mathrm{C}$. Accurate interpretation of the reason behind large shape deviations requires additional research on stamping pressure and correction of the tool's shape. Nevertheless, the smallest shape deviations were obtained using one of the two methods: 1 st strategy heating in the furnace of a temperature of $240{ }^{\circ} \mathrm{C}$ for

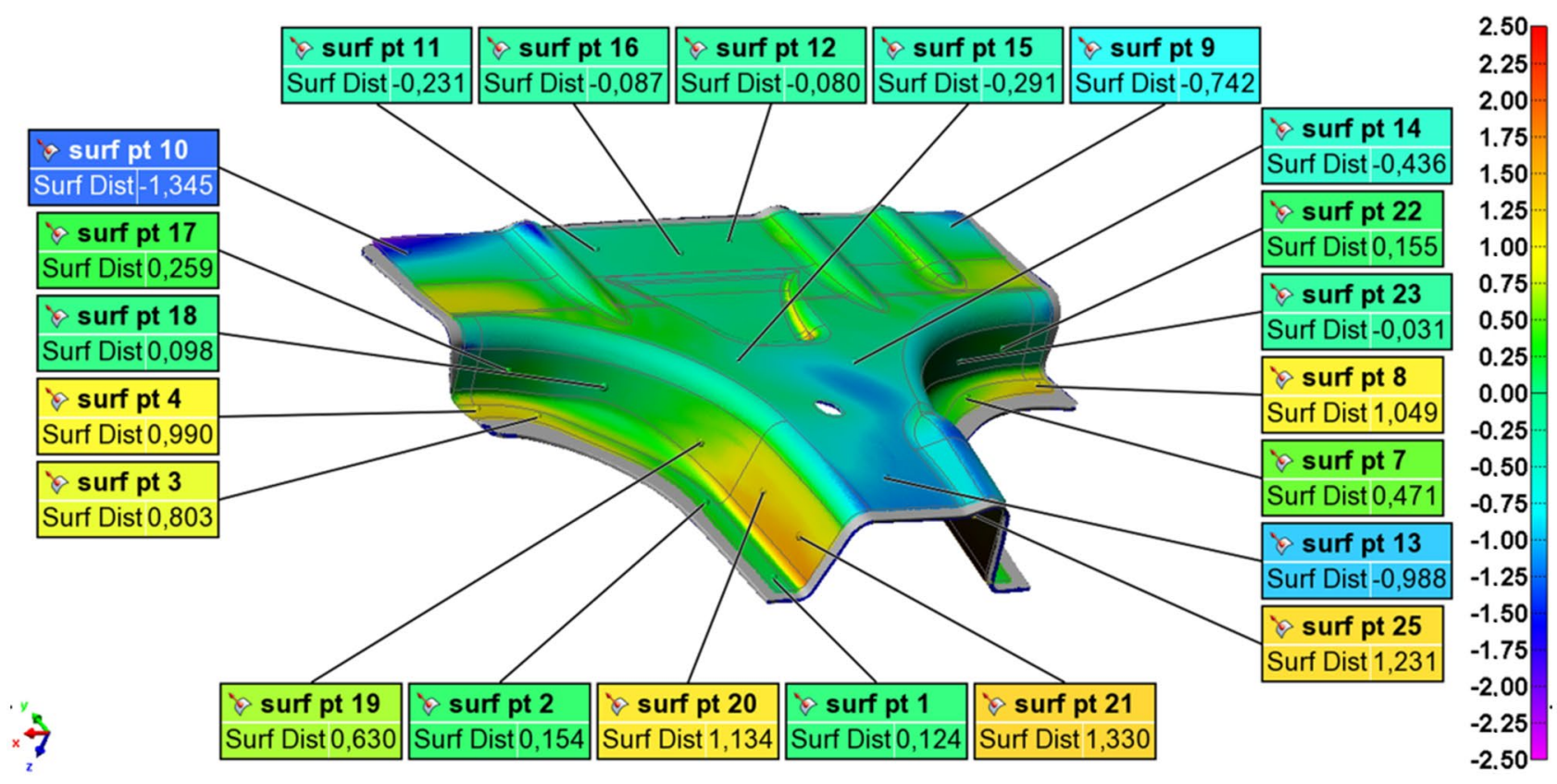

Fig. 10 Shape deviation of the B-pillar's foot 
Fig. 11 Location for hardness measuring (a) U-shaped element, (b) B-pillar's foot
Fig. 12 Location of the specimens (a) U-shaped element, (b) bottom part of B-pillar a)

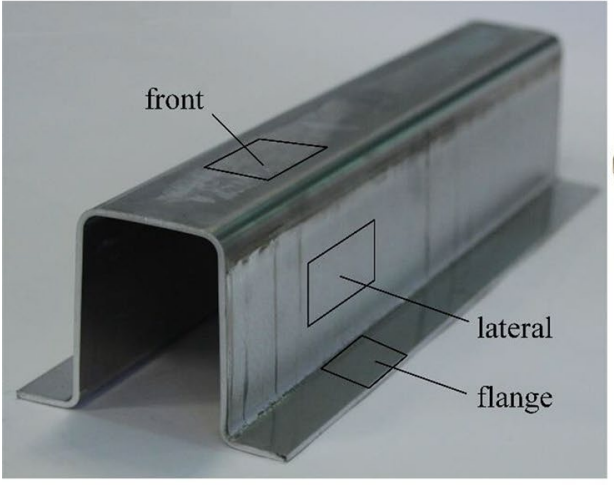

b)

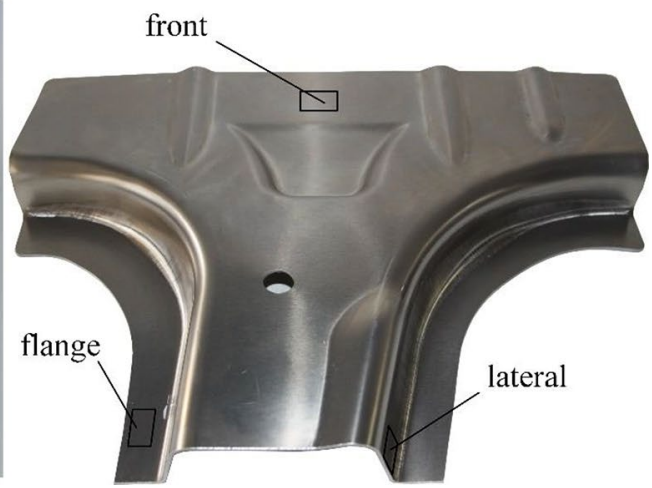

a)

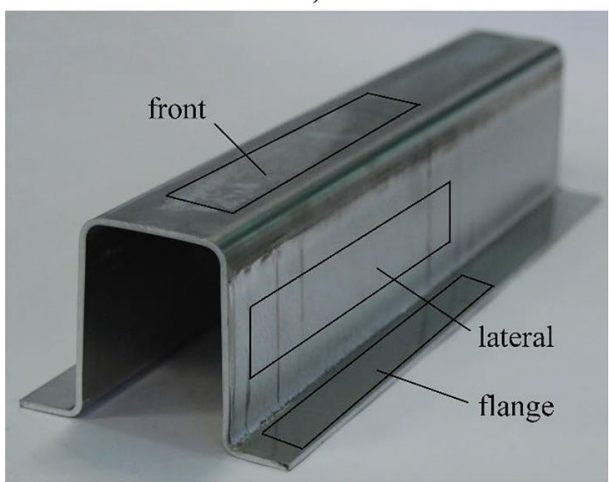

b)

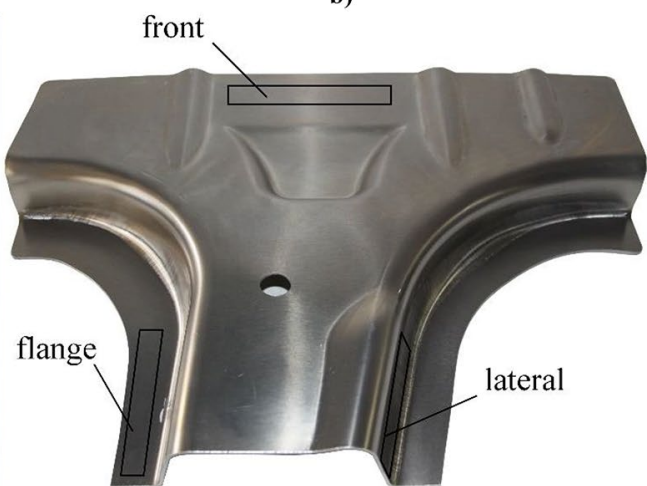

a)

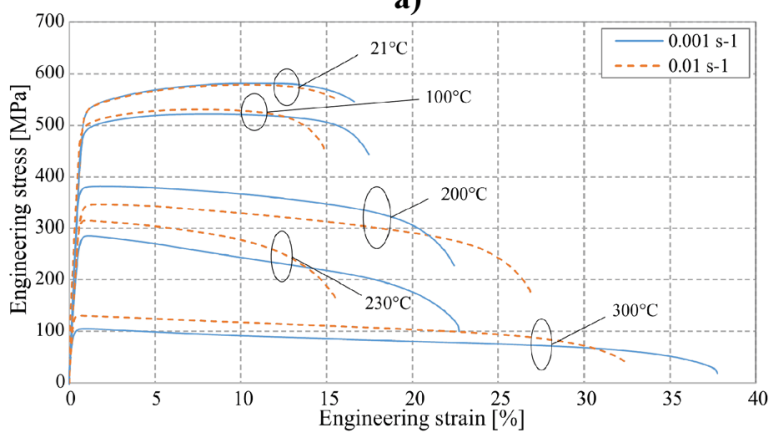

b)

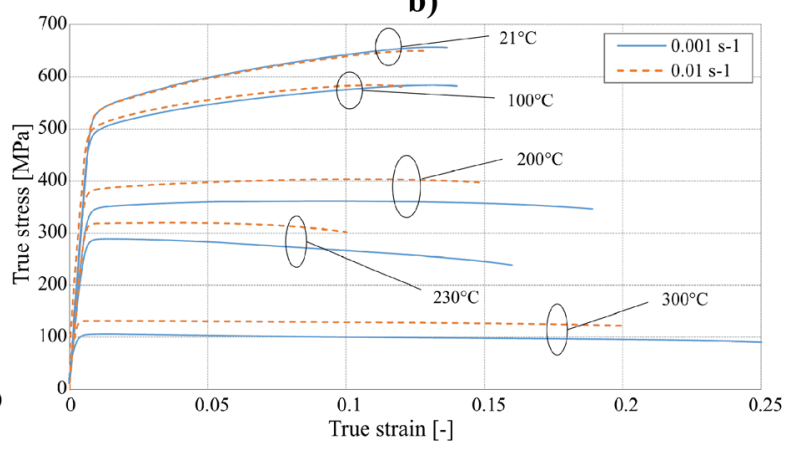

Fig. 13 The influence of the temperature $\left(21-300^{\circ} \mathrm{C}\right)$ on the stress-strain curves of 7075 aluminum alloy (a) engineering curves, (b) true stresstrue strain curves 
Fig. 14 Effect of the heating time at different temperatures on the hardness of 7075 aluminum alloy

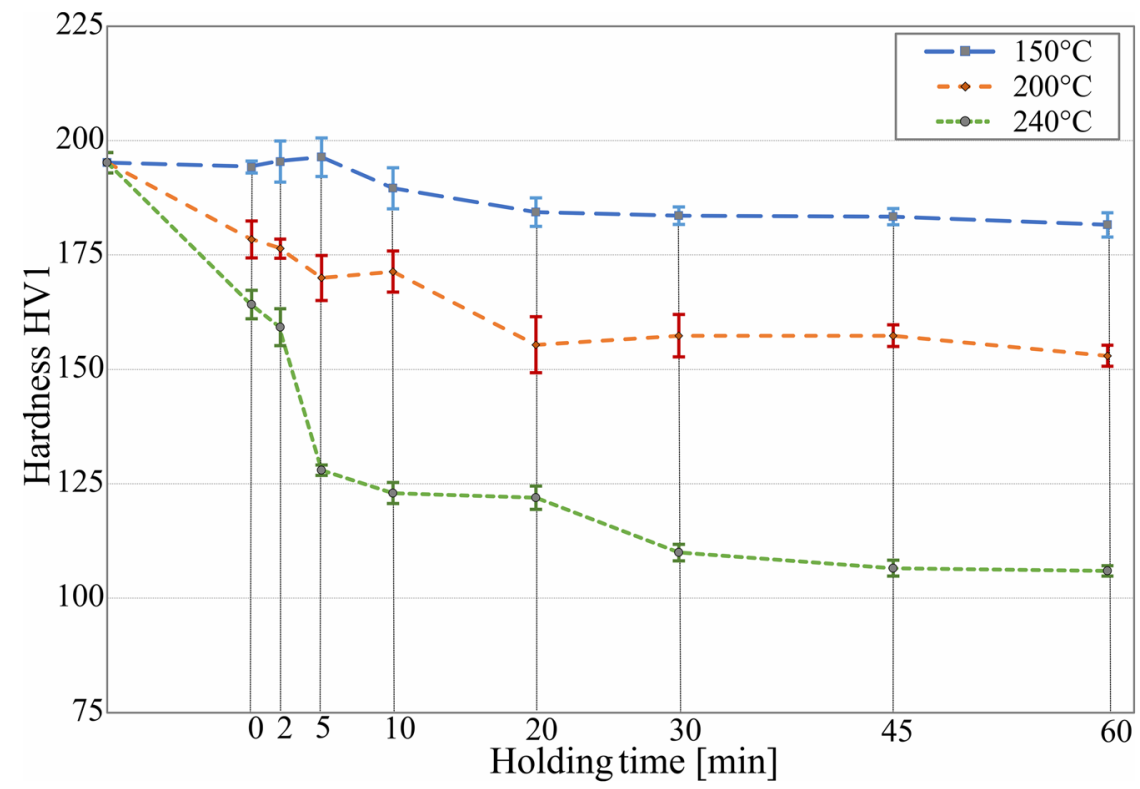

about 35 min (as presented in Fig. 16) or 3rd strategy between the plates of a temperature of $350{ }^{\circ} \mathrm{C}$ for about 1-2 min (as presented in Fig. 17b). Using a $350{ }^{\circ} \mathrm{C}$ hot furnace resulted in an unsatisfactory, excessively large shape deviation (as presented in Fig. 17a).

\subsubsection{Hardness and strength}

Since the strength properties of metal alloys are strictly related to hardness, the final product's hardness was measured first. The results are presented for different heating strategies and test locations as mean values and standard deviations. The influence of blank's temperature on the strength and hardness of U-shape manufactured according to the 1st strategy is shown in Fig. 18a, b. Due to a large amount of data and to ensure the legibility of the presented results, the influence of different heating strategies and blank temperature on the strength of the final product is presented separately. Figure $19 \mathrm{a}-\mathrm{c}$ depicts ultimate tensile strength acquired in different U-shaped locations (front, lateral, and flange). The influence of sheet temperature on the hardness of the products is shown in Fig. 20a, b, and c. The tested temperature range of the sheet was in the range from 150 to $240{ }^{\circ} \mathrm{C}$.

The primary objective of the tests was to achieve strength properties as close as possible to those of the T6 temper of 7075 alloy. Therefore, it was assumed
Fig. 15 The influence of heating method on time needed to heat the blank to the temperature of $240{ }^{\circ} \mathrm{C}$

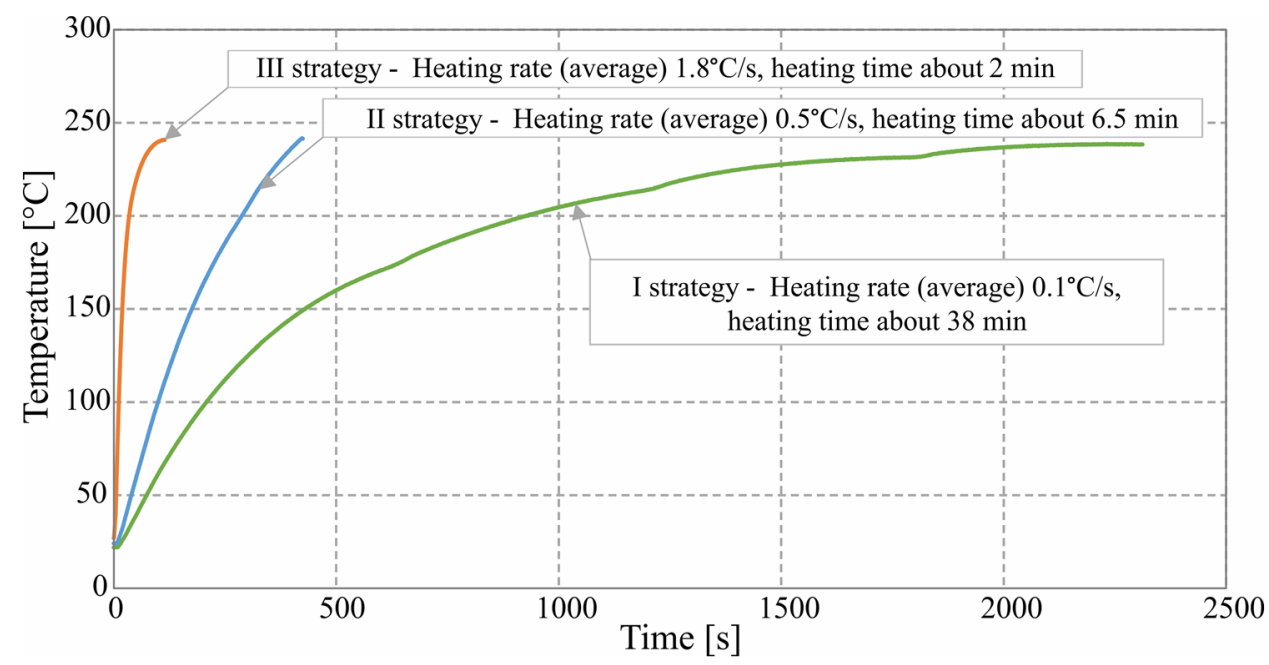


Fig. 16 Shape deviations measured in the cross-section of the U-shape manufactured according to 1 st strategy (furnace temperature, $240{ }^{\circ} \mathrm{C}$; tools temperature, $220^{\circ} \mathrm{C}$ )

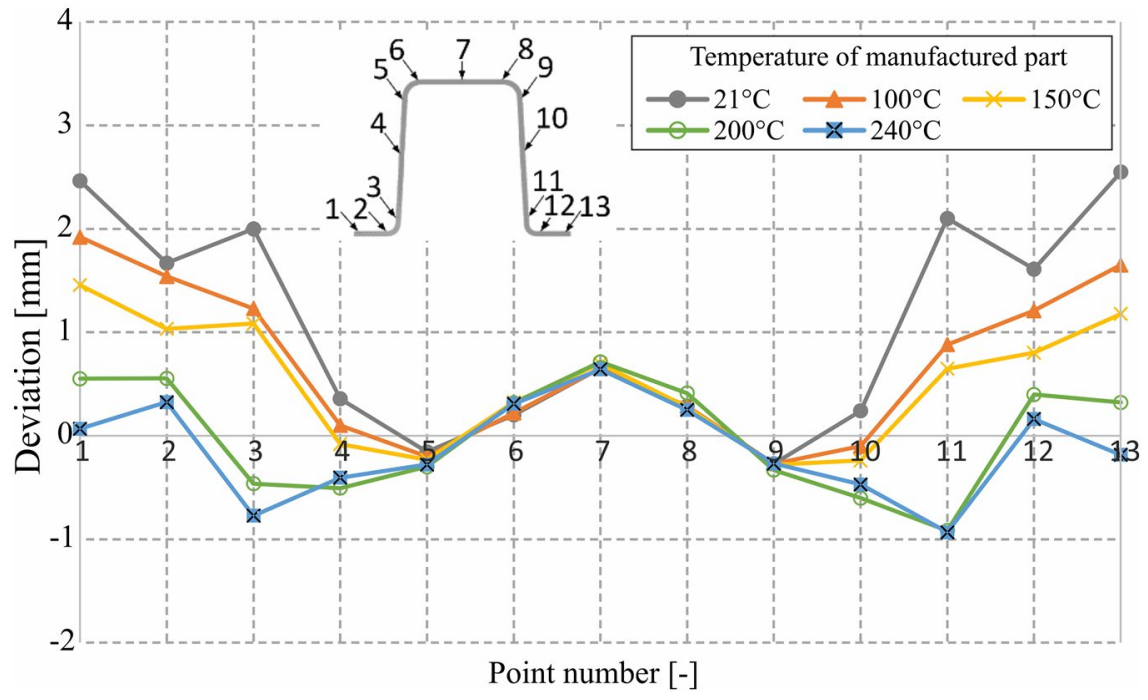

that the desired hardness of the final component should equal to 180-195 HV1, and the ultimate tensile strength $\left(R_{m}\right)$ should be in the range of 540 and $585 \mathrm{MPa}$. Such parameters allow the final products (Table 2) to be used as a car body component. The test results proved that the specimens pre-heated to the temperature from 21 to $150{ }^{\circ} \mathrm{C}$ have the most desirable strength. Unfortunately, these drawpieces are also characterized by the largest shape deviations due to the high springing, as depicted in Fig. 16.

The modification of the heating method allowed to significantly shorten the time during which the material is kept at an elevated temperature. The strength of the final product manufactured according to the 2 nd and 3rd heating strategies varied from 500 to $580 \mathrm{MPa}$ in all areas of the element. As the initial temperature of the sheet increases, the U-shaped strength decreases. This correlation was confirmed by hardness measurements (Fig. $20 \mathrm{a}-\mathrm{c}$ ). In the case of a temperature of $200{ }^{\circ} \mathrm{C}$ (3rd heating strategy - between two hot plates), the strength remains at a satisfactory level (minimum $540 \mathrm{MPa}$ ), and the shape deviations are within the acceptable range of $\pm 1 \mathrm{~mm}$.

\subsection{Tested components - foot of B-pillar}

The obtained results were verified during the manufacturing of the lower part of the B-pillar. For this purpose, three stamping configurations were selected. Each was based on parameters ensuring the highest strength and the lowest shape deviations of the U-shaped product (Table 4). Due to the extensive surface area of the blank, heating of the sheet between the plates was not applied. It would cause excessive shrinkage and bending of the blank due to uneven dissipation of the heat. Therefore, only the 1 st and 2 nd heating strategies were used while stamping the B-pillar's foot. a)

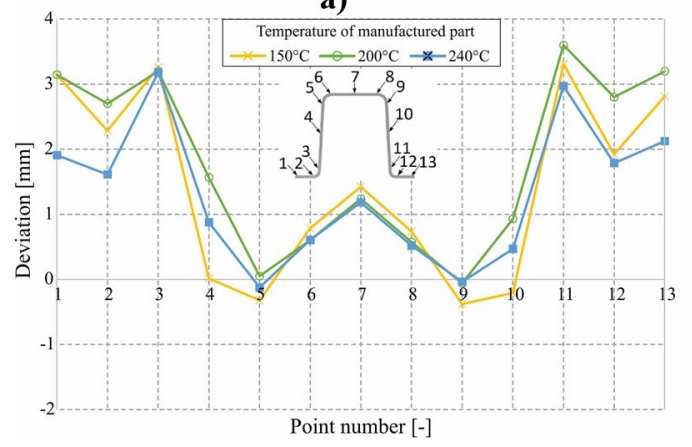

b)

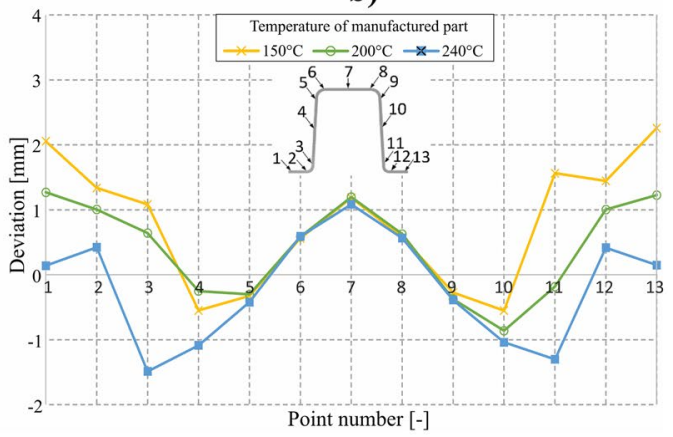

Fig. 17 Shape deviations measured in the cross-section of the U-shape (a) 2nd strategy, (b) 3rd strategy 
Fig. 18 The influence of the blank temperature on the U-shaped element manufactured according to 1 st strategy (a) strength, (b) hardness of finished product (1st strategy)
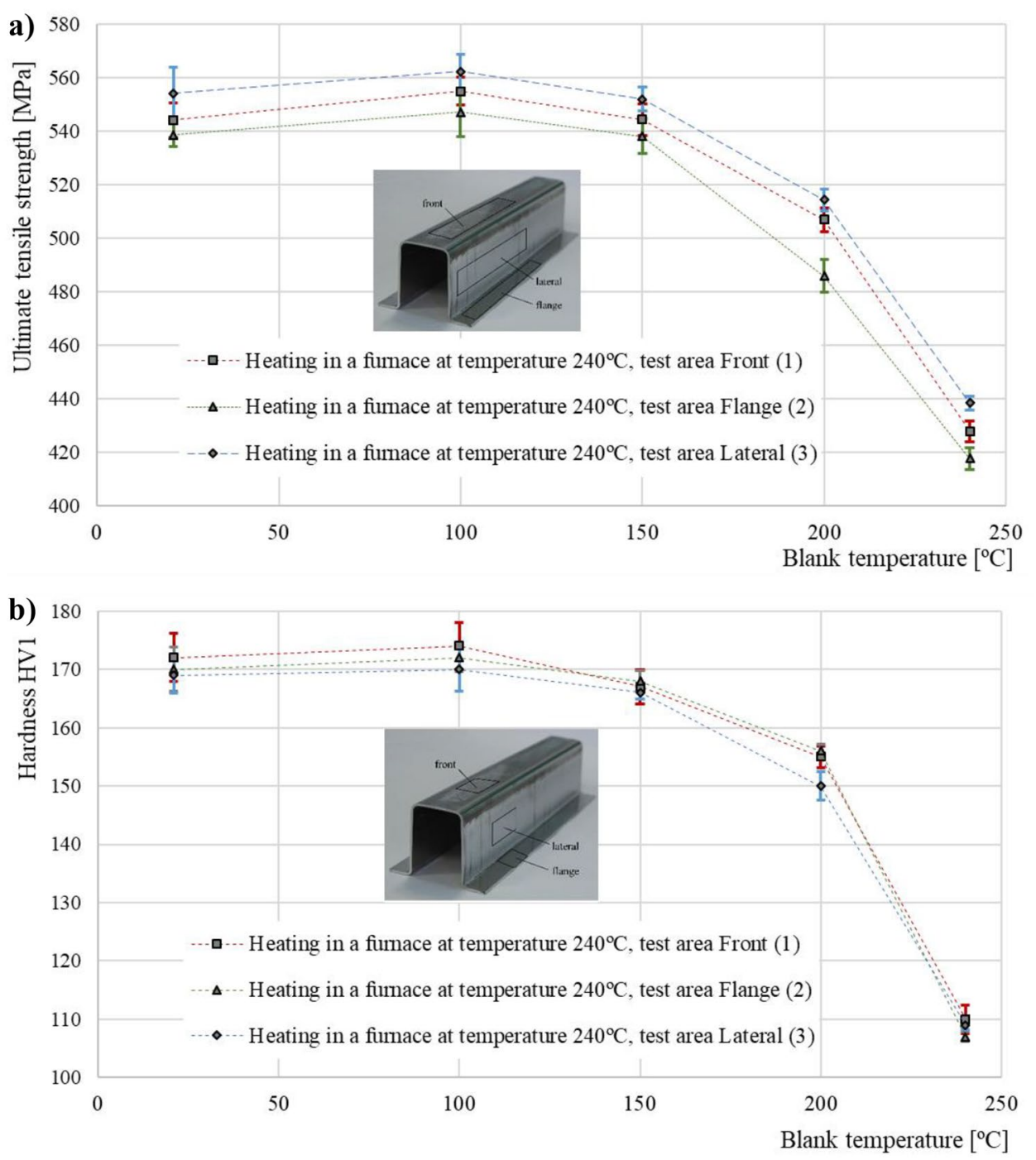

\subsubsection{Measurement of shape deviations}

Figures 21, 22 and 23 depict the measured shape deviations at the reference points. The deviations were determined by comparing the scanned surfaces and the CAD model using the "best-fit" strategy.

Based on the measured deviations, it was observed that the blank made according to 1st strategy falls within the permissible deviations of $\pm 1 \mathrm{~mm}$, except for points no. 4 , $8,10,20,21$, and 25 (Fig. 21). The negative shape deviation of measuring point no. 10 proves that a slight bending of the sheet during manual transfer (using pliers) from the heating stand to the stamping tools occurred. On the other hand, the positive deviation of points 20,21 , and 25 is related to the material springing. The process is not very intense but occurs during the heat treatment. Similar conclusions were drawn in the case of blanks made according to 2nd heating strategy (Fig. 22 - sheet temperature $240{ }^{\circ} \mathrm{C}$, Fig. 23 - sheet temperature $200^{\circ} \mathrm{C}$ ). The drawpiece manufactured at $200{ }^{\circ} \mathrm{C}$ has the smallest number of points deviating more than $\pm 1 \mathrm{~mm}$ from the nominal geometry, and these exceedances were small (points no. 10 : $-1.34 \mathrm{~mm}, 20-1.13 \mathrm{~mm}, 21-1.33 \mathrm{~mm}, 25-1.23 \mathrm{~mm}$ ). The shape of the drawpiece can be additionally corrected by adjusting the tool's geometry and automating the transportation method of the blank. 
Fig. 19 The influence of the heating strategy on the strength of the U-shaped product (a) front, (b) flange, (c) lateral
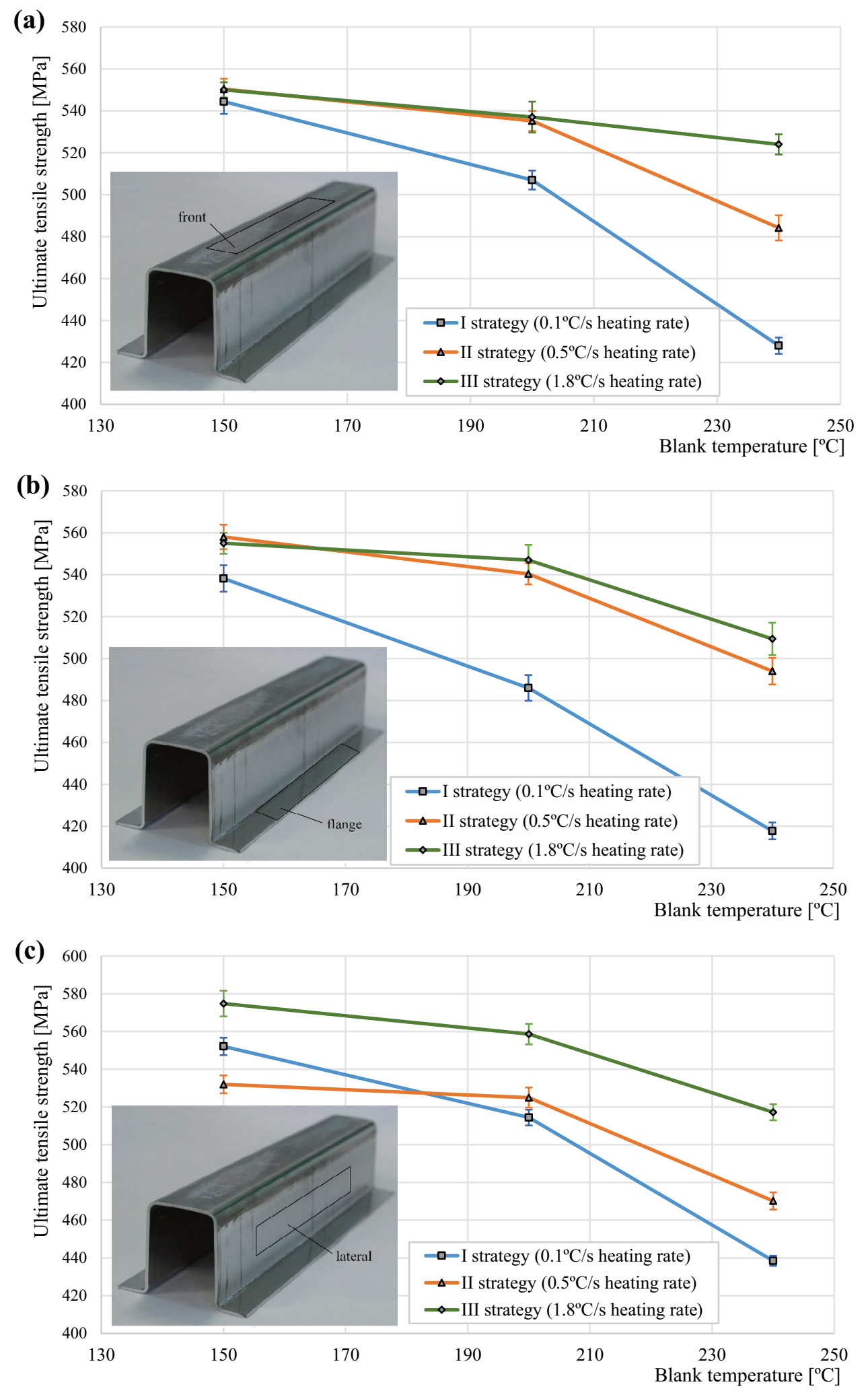
Fig. 20 The influence of the heating strategy on the hardness of the U-shaped product (a) front, (b) flange, (c) lateral
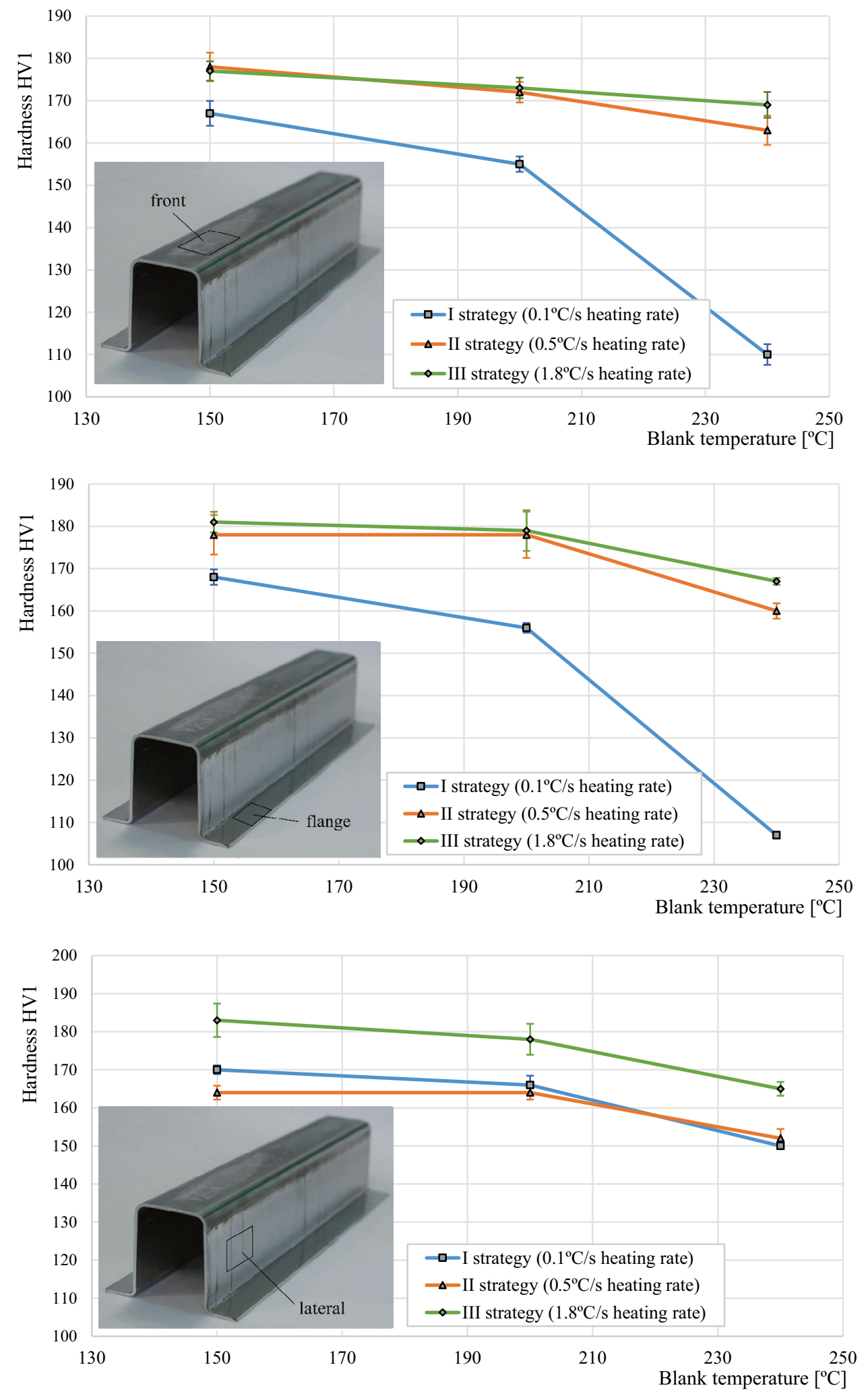
Table 4 Forming parameters of the B-pillar's foot

\begin{tabular}{llll}
\hline Heating strategy & 1st strategy & 2nd strategy & 2nd strategy \\
\hline Temperature of furnace & $240{ }^{\circ} \mathrm{C}$ & $350{ }^{\circ} \mathrm{C}$ & $350{ }^{\circ} \mathrm{C}$ \\
Temperature of blank & $240{ }^{\circ} \mathrm{C}$ & $240{ }^{\circ} \mathrm{C}$ & $200{ }^{\circ} \mathrm{C}$ \\
\hline
\end{tabular}

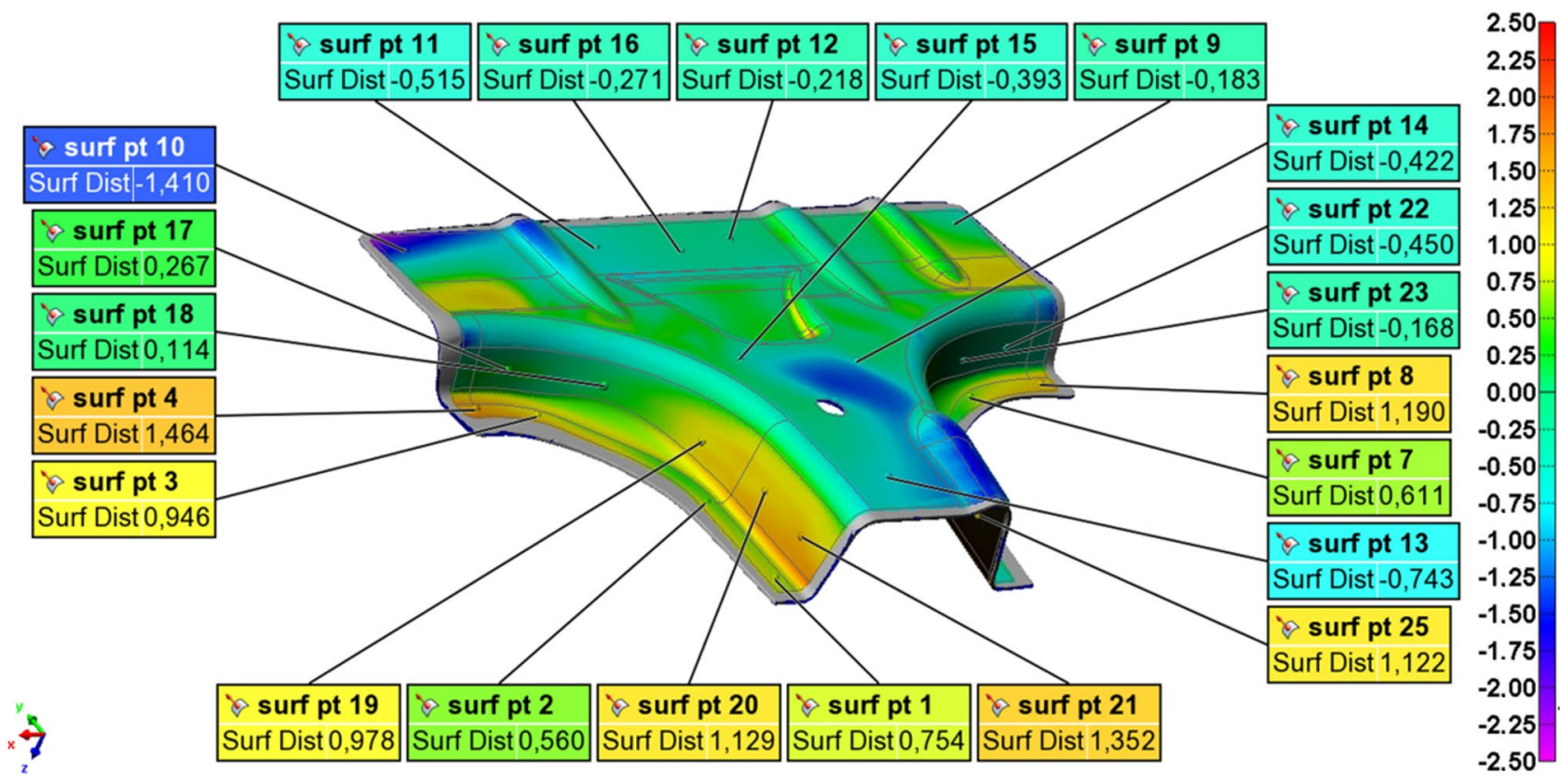

Fig. 21 Shape deviations of the B-pillar's foot stamped from the blank pre-heated to $240{ }^{\circ} \mathrm{C}\left(1\right.$ st strategy — heating in the furnace $\left.240{ }^{\circ} \mathrm{C}\right)$

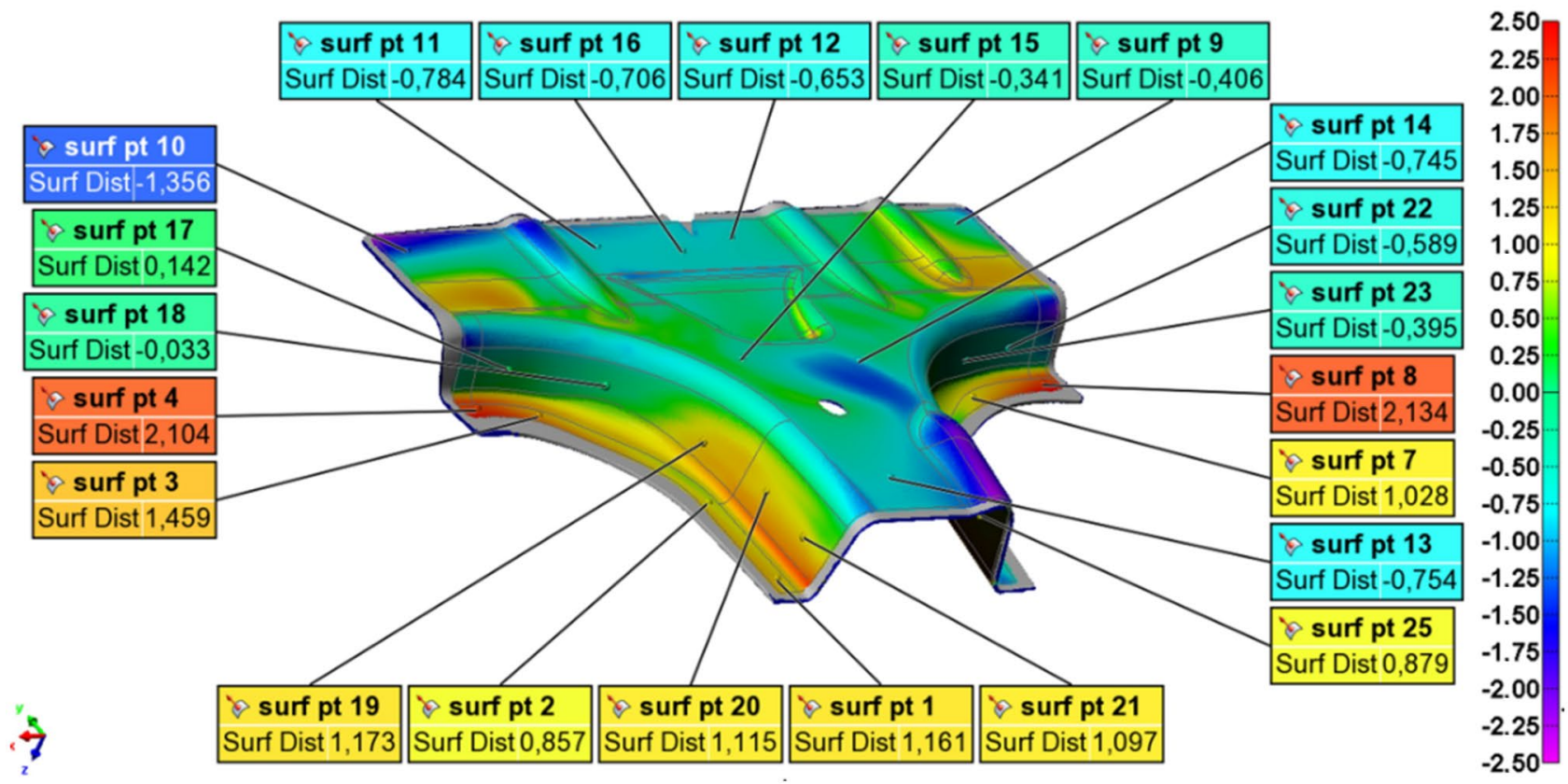

Fig. 22 Shape deviations of the B-pillar's foot stamped from the blank pre-heated to $240{ }^{\circ} \mathrm{C}\left(2 \mathrm{nd}\right.$ strategy — heating in the furnace $\left.350{ }^{\circ} \mathrm{C}\right)$ 


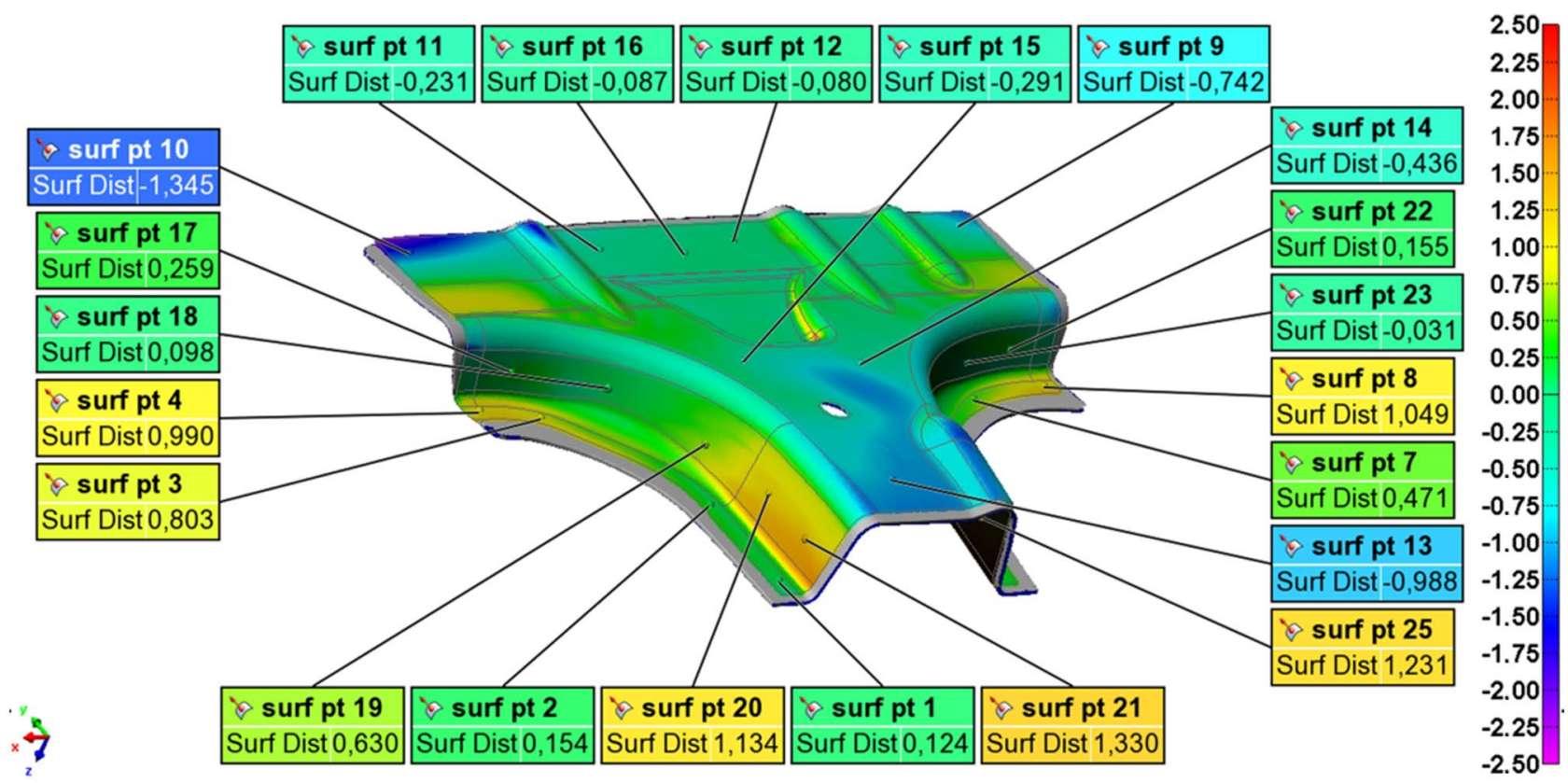

Fig. 23 Shape deviations of the B-pillar's foot stamped from the blank pre-heated to $200{ }^{\circ} \mathrm{C}\left(2 \mathrm{nd}\right.$ strategy - heating in the furnace $\left.350{ }^{\circ} \mathrm{C}\right)$

In conclusion, the dominant form of the deformation after removing the B-pillar's foot from the forming tools was bending. On the other hand, the lowest deviations are obtained for the blank temperature equal to $200{ }^{\circ} \mathrm{C}$ (Fig. 23). It was additionally observed that the heating time did not significantly affect the obtained shape deviations.

\subsubsection{Hardness and strength}

Figures 24 and 25 depict the hardness and strength properties of different areas of the B-pillar's foot. The hardness and strength are mean values calculated using at least 5 drawpieces produced according to the same heating strategy.

Like in the case of the U-shape, stamping the blank heated up to $240{ }^{\circ} \mathrm{C}$ (Fig. $25-1$ st strategy) did not provide sufficient strength of the final product (hardness 140-150 HV1 and the ultimate tensile strength $450 \mathrm{MPa})$. Shortening the heating time and maintaining the blank temperature of $240{ }^{\circ} \mathrm{C}$ (Fig. $25-2$ nd strategy) allows obtaining decidedly higher strength parameters (hardness 151-158 HV 1 and the ultimate tensile strength 470-492 MPa). Further lowering the temperature of the blank to $200{ }^{\circ} \mathrm{C}$ leads to an increase in strength and hardness and a significant decrease in the material's formability. This results in defects in the form of thickness reduction, material cracks, and local folding (Fig. 26).

\subsubsection{Microstructure}

Specimens were cut out from a T6 temper 7075 aluminum alloy sheet and from a drawpiece of the highest strength (made according to $2 \mathrm{nd}$ strategy: blank temperature $200^{\circ} \mathrm{C}$, furnace temperature $350^{\circ} \mathrm{C}$ ) and used for structural testing. The specimens were taken from the least and most deformed regions (Fig. 27).
Fig. 24 The influence of the heating strategy on the ultimate tensile strength of different areas of the B-pillar's foot

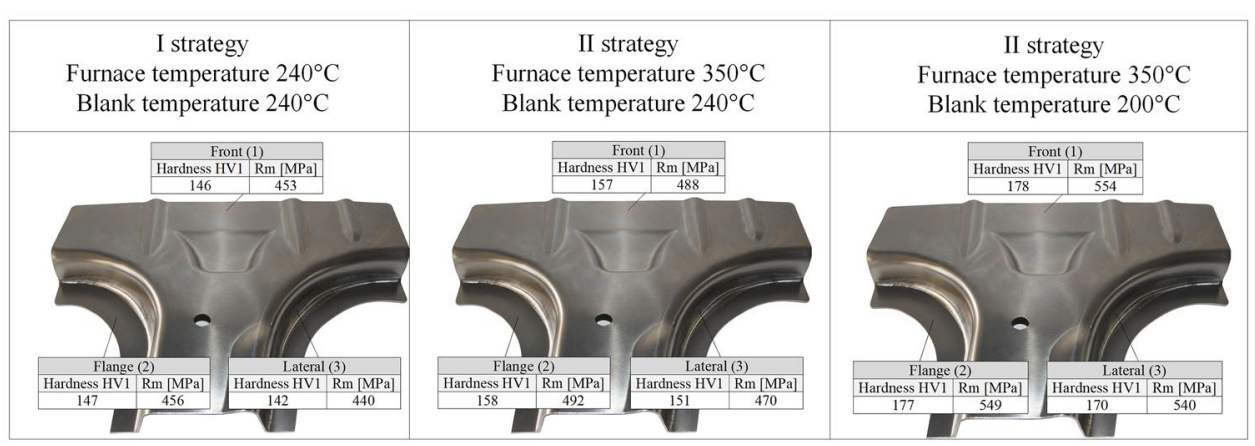


Fig. 25 The influence of the heating strategy on the stressstrain curves of different areas of the B-pillar's foot

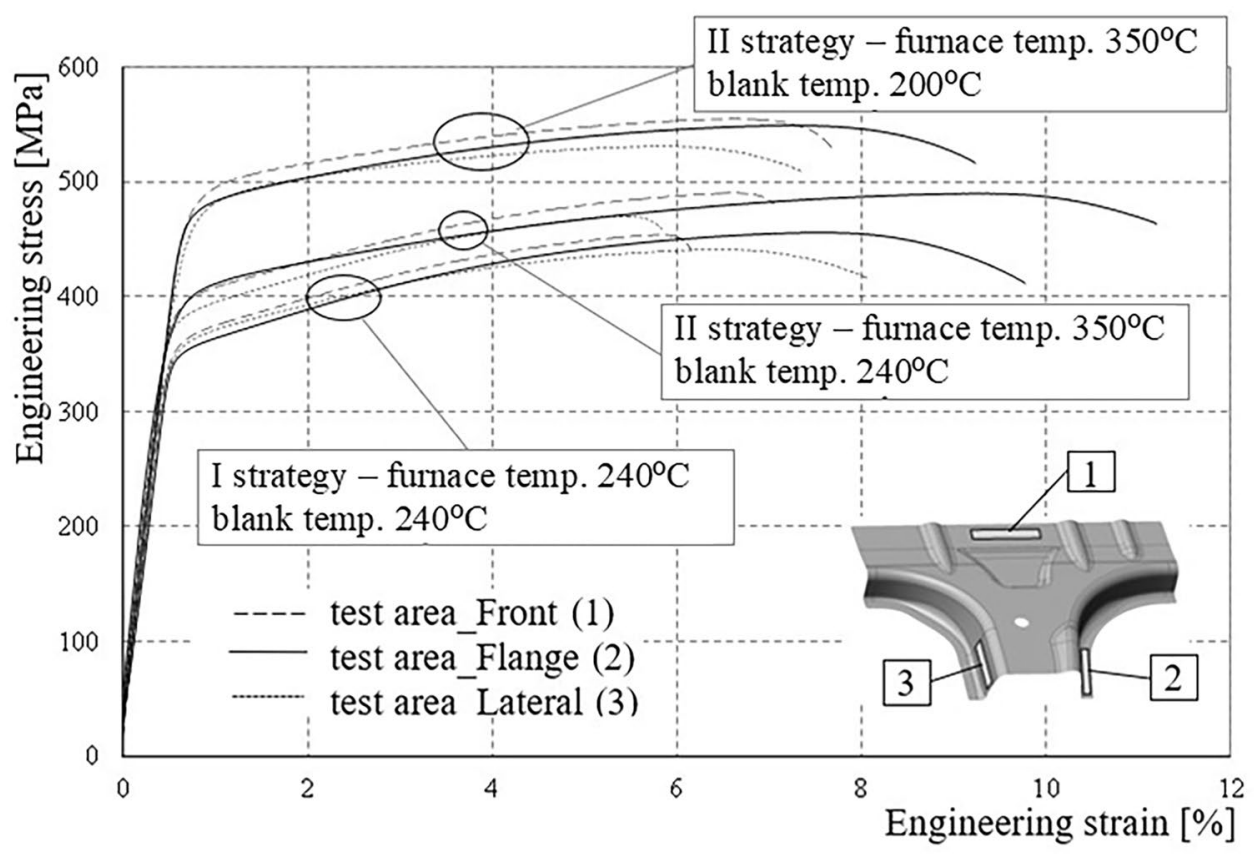

Fig. 26 Selected defects resulting from the stamping process (blank temperature $200{ }^{\circ} \mathrm{C}$ )
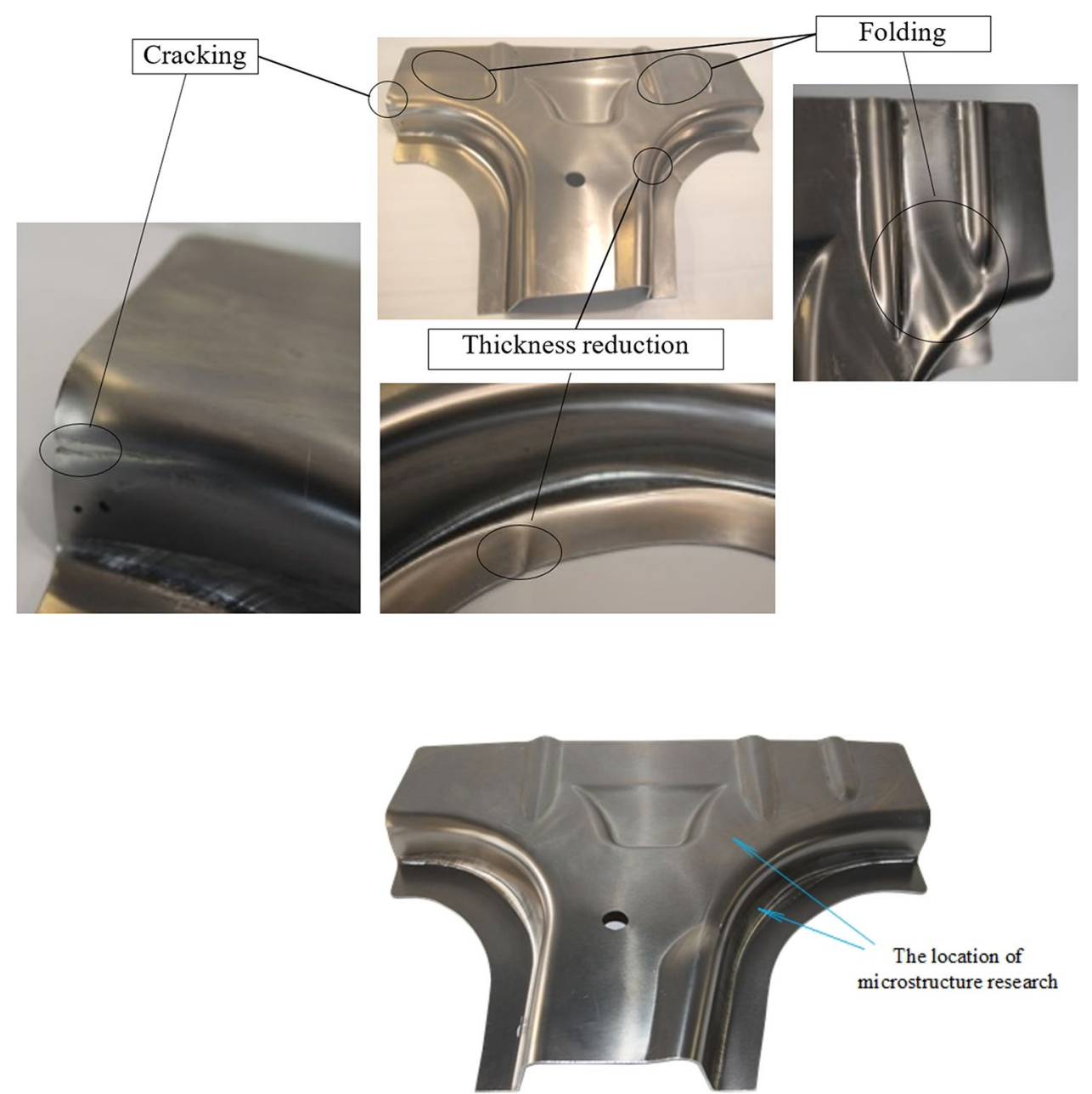

Fig. 27 Microstructure testing locations 
Fig. 28 The microstructure of as-delivered T6 temper 7075 aluminum alloy
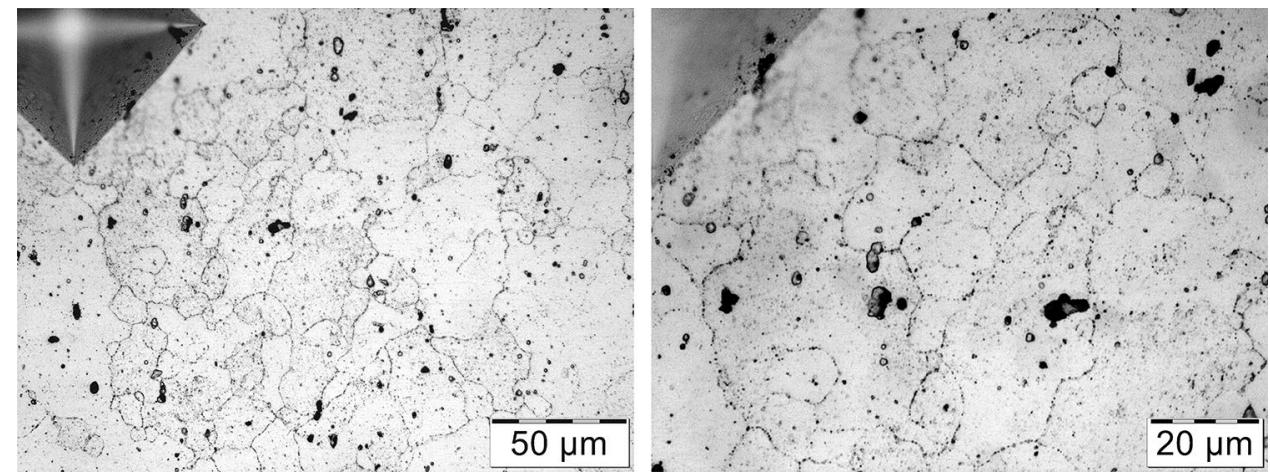

Fig. 29 The microstructure of 7075 aluminum alloy after heating at $200{ }^{\circ} \mathrm{C}$ for $6.5 \mathrm{~min}$ and forming
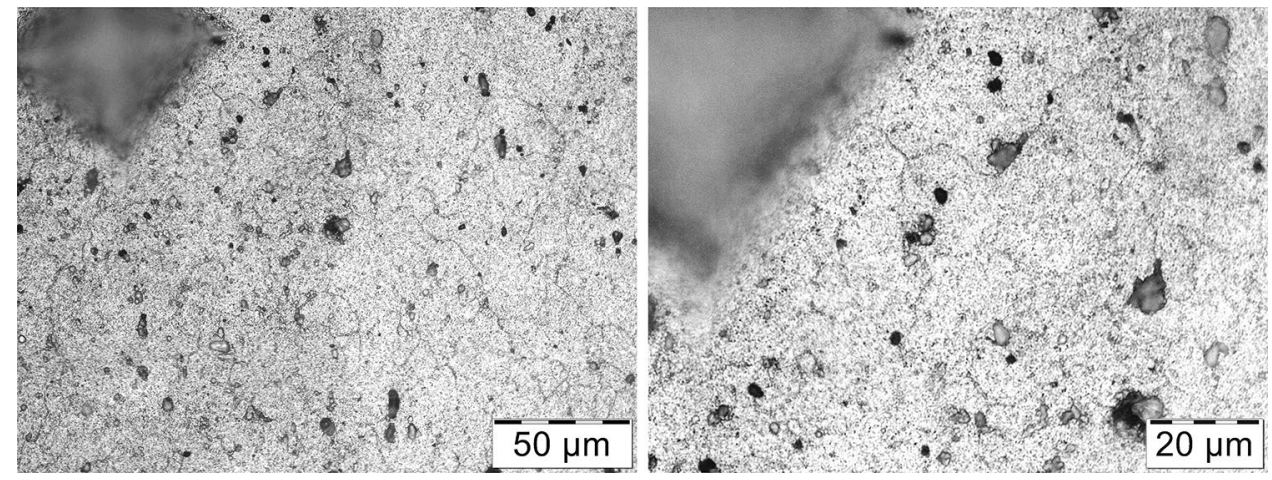

In the first stage of microstructural testing, the effect of heating the material to $200{ }^{\circ} \mathrm{C}$ (below the recrystallization temperature) was checked on optical microscopy, revealing the grain size changes. The material in as-delivered T6 temper is depicted in Fig. 28, while the structure after forming at $200{ }^{\circ} \mathrm{C}$ is presented in Fig. 29.

By comparing two metallographic images (Figs. 28 and 29), it can be deduced that heating the material to $200{ }^{\circ} \mathrm{C}$ and forming does not cause a change in grain size. The prolonged heating (for $7 \mathrm{~min}$ at $200{ }^{\circ} \mathrm{C}$ ) results in phase coagulation (Fig. 29) and lower hardness of the alloy (Fig. 18).

In the second stage of microstructural research, the effect of heating the material at $200{ }^{\circ} \mathrm{C}$ on the presence and size of strengthening precipitates was checked. The microstructure of the 7075 aluminum alloy in as-delivered T6 temper (Fig. 30) consists of $\alpha$ matrix and the solid solution of small precipitates formed during artificial aging at elevated temperature. The mechanical properties of 7075 alloy depend on nanostructural precipitations' type, size, and distribution [30]. In most references, it is reported that the usual precipitation sequence after solution treatment goes as follows [31]:

$$
S S S \rightarrow \text { GPzone } \rightarrow \eta^{\prime} \rightarrow \eta(M g Z n 2)[32,33] .
$$

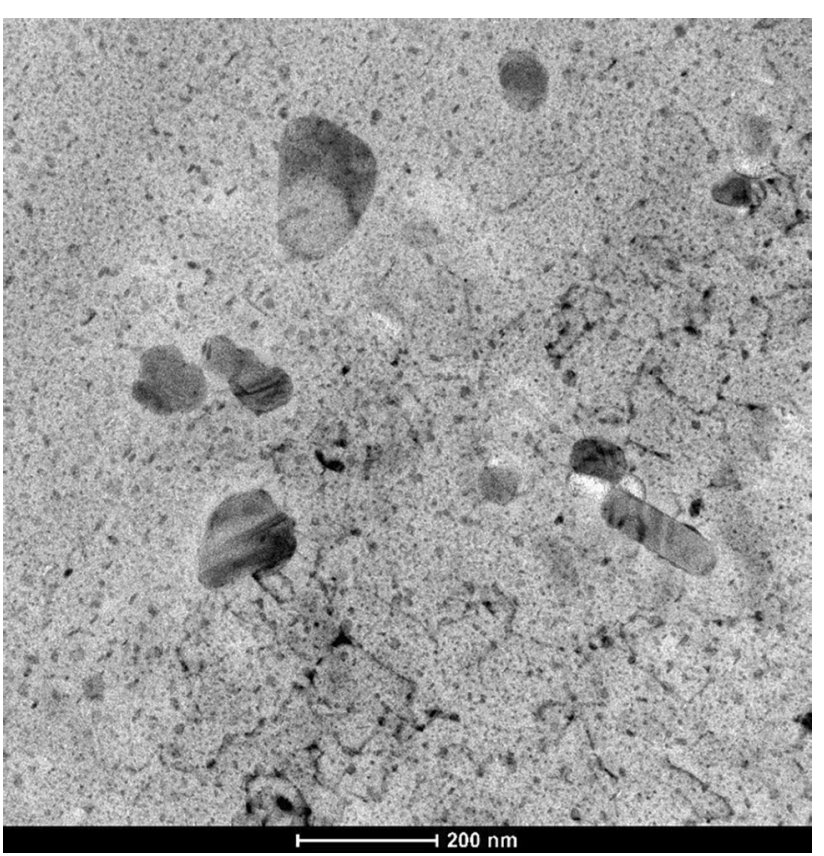

Fig. 30 The microstructure of T6 temper 7075 aluminum alloy, bright-field images

The microstructure analysis confirms that the primary precipitation is metastable hexagonal $\eta^{\prime}$ phase, which is semi-coherent with the aluminum matrix. However, a 
Fig. 31 Precipitations of T6 temper (a) bright-field (BF) image, (b) dark-field (DF) diffraction pattern of area $1-$ $\mathrm{MgZn}_{2}$ phase, (c) dark-field diffraction pattern of area 2 $\mathrm{Al}_{18} \mathrm{Mg}_{3} \mathrm{Cr}_{2}$ phase a)
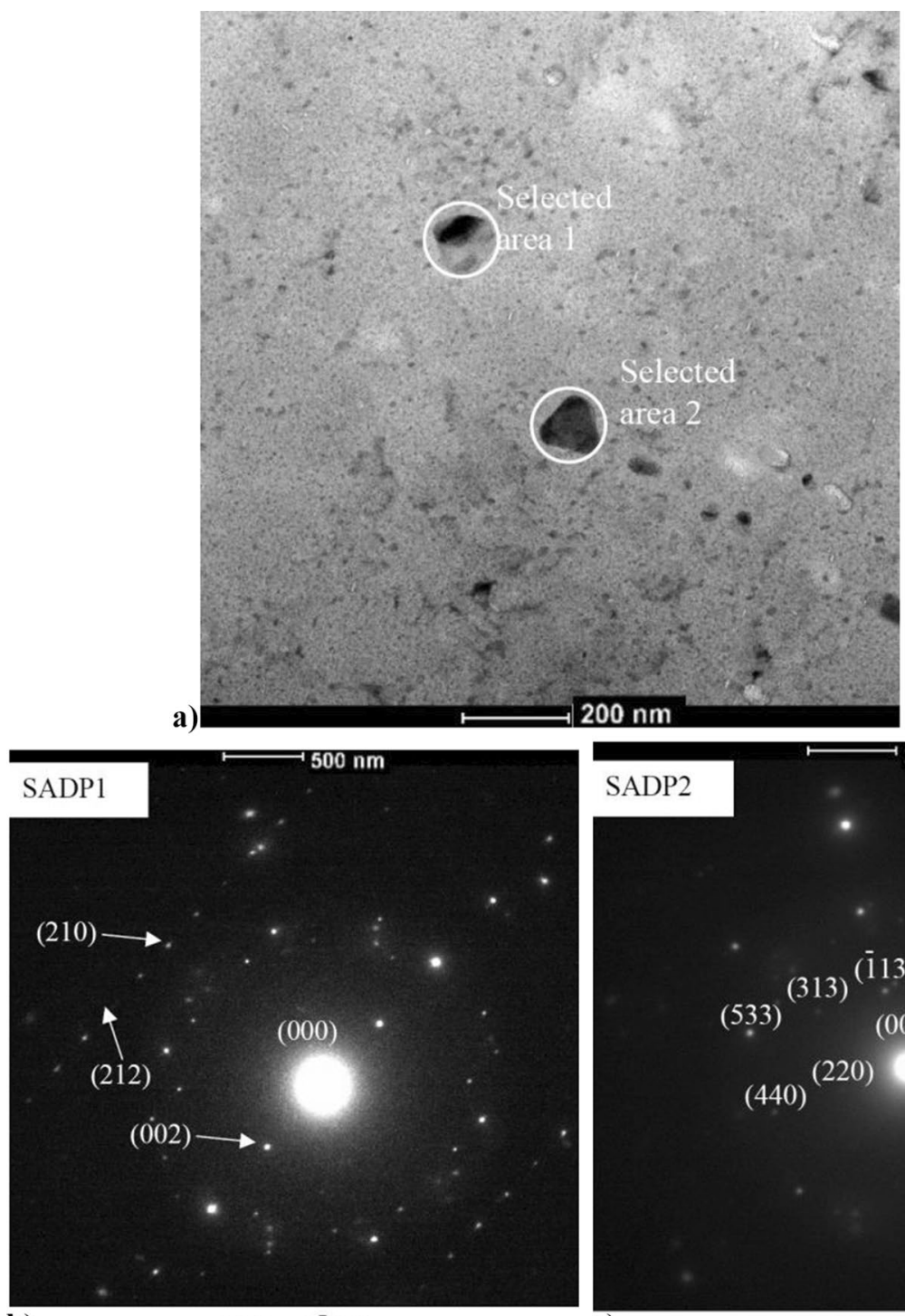

b)

$\mathrm{MgZn}_{2}[120]$

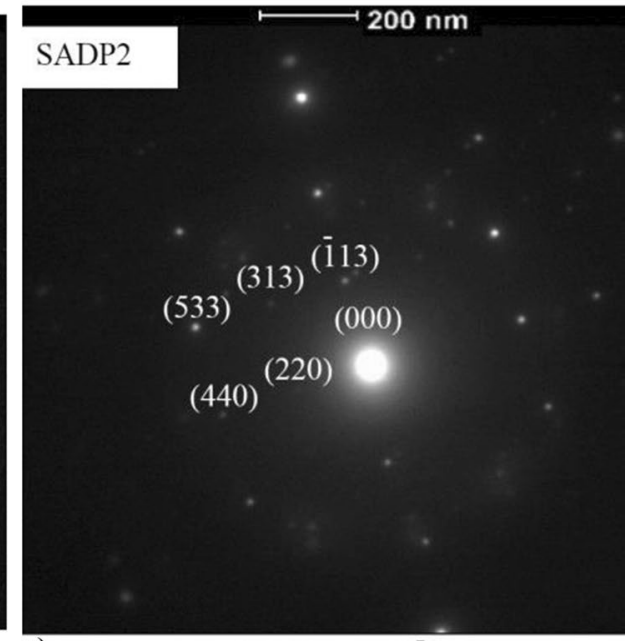

$\mathrm{Al}_{18} \mathrm{Mg}_{3} \mathrm{Cr}_{2}$ [332] small amount of $\mathrm{Al}_{18} \mathrm{Mg}_{3} \mathrm{Cr}_{2}$ precipitations was observed (Fig. 31). The quantitative analysis of the precipitates was also carried out. The share of the precipitates was $9.4 \%$, the average size of the precipitates was $153 \mathrm{~nm}^{2}$ with a standard deviation of $19.5 \mathrm{~nm}^{2}$, and the largest particle's size was equal to $180 \mathrm{~nm}^{2}$.
The microstructure of 7075 aluminum alloy sheet heated up to $200{ }^{\circ} \mathrm{C}$ (in the furnace of a temperature of $350{ }^{\circ} \mathrm{C}$ ) and immediately formed is depicted in Fig. 32. It proves that there are no significant changes in the distribution of precipitation during heating and forming. The quantitative analysis of the precipitates proves slight changes in the microstructure. The 


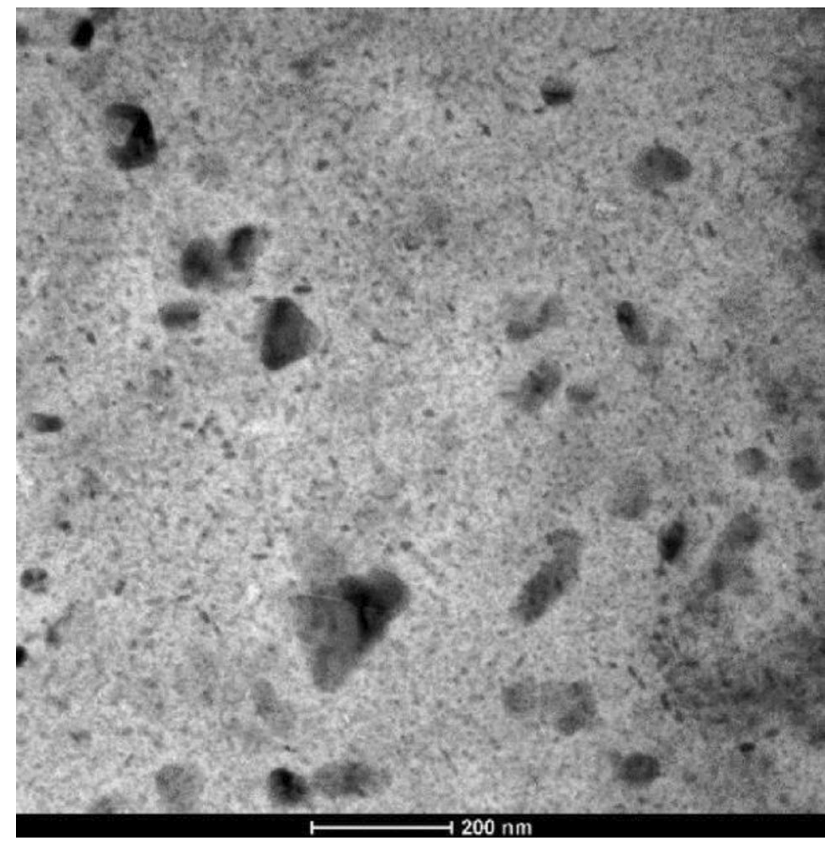

Fig. 32 The microstructure of 7075 aluminum alloy sheet heated up to $200{ }^{\circ} \mathrm{C}$ (in the furnace of a temperature of $350{ }^{\circ} \mathrm{C}$ ) and formed bright-field images

share of the precipitates was $7.5 \%$, the average size of the precipitates was $145 \mathrm{~nm}^{2}$ with a standard deviation of 65 $\mathrm{nm}^{2}$, and the largest particle's size was equal to $220 \mathrm{~nm}^{2}$. Increased standard deviation and size of the largest particle could be responsible for a slight decrease in hardness and tensile strength of the material (in comparison with $\mathrm{T} 6$ temper). Except for the $\mathrm{MgZn}_{2}$ phase, the $\mathrm{Al}_{18} \mathrm{Mg}_{3} \mathrm{Cr}_{2}$ phase varying from several to above $200 \mathrm{~nm}$ was found. Additionally, $\mathrm{Fe}_{6,4}$ $\mathrm{Al}_{12}, 59$ and probably other phases (Fig. 33) were analyzed. Their size usually equals several nanometers and has no significant effect on mechanical properties.

\section{Conclusion}

Based on the conducted research, the following conclusions have been drawn:

1. Cold forming a 3-mm-thick T6 temper 7075 aluminum alloy sheet is practically impossible. It is necessary to form elements at an elevated temperature. Increasing the temperature and heating time causes deterioration of the material's strength and hardness.

2. Holding 7075 alloy at $240{ }^{\circ} \mathrm{C}$ for 2 min after reaching the set temperature cause rapid hardness decrease (from the initial value of $195 \mathrm{HV} 1$ to about $155 \mathrm{HV} 1$ ), and holding for $5 \mathrm{~min}$ after reaching the set temperature results in the hardness decreasing to $125 \mathrm{HV} 1$. Reducing the temperature to $200{ }^{\circ} \mathrm{C}$ results in maintaining higher strength parameters. After holding for $60 \mathrm{~min}$, the hardness was equal to $155 \mathrm{HV} 1$, while $10 \mathrm{~min}$ holding time allowed to retain the hardness of about $170 \mathrm{HV} 1$. At a temperature of $150{ }^{\circ} \mathrm{C}$, the hardness decrease was observed after $5 \mathrm{~min}$, but the final hardness after $60 \mathrm{~min}$ of holding was equal to $185 \mathrm{HV} 1$. Stamping of complex elements was difficult at this temperature, but a simple bending was still possible.

3. In the case of U-shaped bending, the 1st heating strategy provided the highest strength parameters. Blanks pre-heated to $21,100,150{ }^{\circ} \mathrm{C}$ were characterized by ultimate tensile strength greater than $540 \mathrm{MPa}$. Unfortunately, their geometry was also inaccurate (shape deviations were exceeding the allowable value of $\pm 1 \mathrm{~mm}$ ), due to excessive springing. Shortening the heating time to $6.5 \mathrm{~min}$ (2nd heating strategy, heating rate equal to $0.5^{\circ} \mathrm{C} / \mathrm{s}$ ) and preheating the blanks to 150 or $200{ }^{\circ} \mathrm{C}$ allowed to obtain high-strength products (UTS $\geq 540 \mathrm{MPa}$ ). In the case of the 2 nd heating strategy, the shape deviation of all products, regardless of
Fig. 33 The image of the area selected for testing diffraction pattern (SADP) (a) bright-field (BF) image, (b) dark-field (DF) diffraction pattern of indicated area $-\mathrm{Fe}_{6,4} \mathrm{Al}_{12,59}$ phase
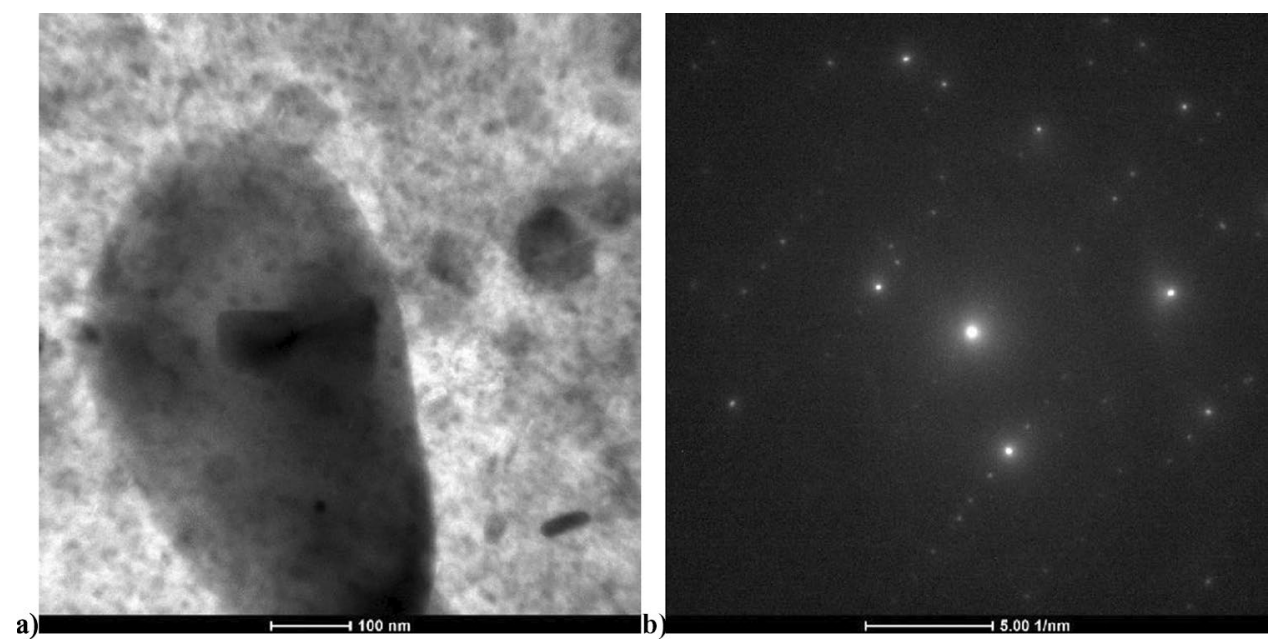
the blank temperature, was significantly exceeding the permissible range of $\pm 1 \mathrm{~mm}$. Only the 3 rd heating strategy (between plates, 2 min heating time, heating rate of $0.1{ }^{\circ} \mathrm{C} / \mathrm{s}$ ) allowed to obtain a product that meets both strength and geometry requirements (for blank temperatures of 200 and $240{ }^{\circ} \mathrm{C}$ ).

4. Stamping the B-pillar's foot according to the 1st and 2nd heating strategy (blank temperature was equal to $240{ }^{\circ} \mathrm{C}$ ) resulted in the product's strength below $500 \mathrm{MPa}$. Lowering the blank temperature to $200{ }^{\circ} \mathrm{C}$ (2nd strategy) allowed to meet the strength requirements (min. $540 \mathrm{MPa}$ ). Geometry deviation was at most $\pm 1.34 \mathrm{~mm}$, which can be optimized by automating the transfer of finished blank and slight adjustment of the forming tools.

5. Microscopic observations proved that heating the material to $200{ }^{\circ} \mathrm{C}$ for $6.5 \mathrm{~min}$ using the rapid heating method (2nd strategy, furnace temperature equal to $350{ }^{\circ} \mathrm{C}$ ) does not change the material's grain size. On the other hand, electron microscopy showed that neither the number nor the size of the strengthening particles $\left(\mathrm{MgZn}_{2}\right.$, $\mathrm{Al}_{18} \mathrm{Mg}_{3} \mathrm{Cr}_{2}$ ) changes due to such heat treatment, which ensures the high strength of the 7075 aluminum alloy.

6. Considering final geometry and strength properties, heating the material to $200{ }^{\circ} \mathrm{C}$ for $6.5 \mathrm{~min}$ using the rapid heating method (2nd strategy, furnace temperature equal to $350{ }^{\circ} \mathrm{C}$ ) is the best technology.

7. The collected data may be used for FEM modeling of stamping processes to propose shape correction of the tools. This would allow meeting all of the shape and dimensional requirements.

Acknowledgements This research was founded by the National Centre for Research and Development, grant no. POIR.04.01.04-00-0088/15 "Development of press-forming technology for manufacturing B-pillars from 7xxx-series aluminum alloys."

\section{Declarations}

Ethics approval Not applicable.

Consent to participate Not applicable.

Consent for publication Not applicable.

Conflict of interest The authors declare no competing interests.

Open Access This article is licensed under a Creative Commons Attribution 4.0 International License, which permits use, sharing, adaptation, distribution and reproduction in any medium or format, as long as you give appropriate credit to the original author(s) and the source, provide a link to the Creative Commons licence, and indicate if changes were made. The images or other third party material in this article are included in the article's Creative Commons licence, unless indicated otherwise in a credit line to the material. If material is not included in the article's Creative Commons licence and your intended use is not permitted by statutory regulation or exceeds the permitted use, you will need to obtain permission directly from the copyright holder. To view a copy of this licence, visit http://creativecommons.org/licenses/by/4.0/.

\section{References}

1. Han J, Paidar M, Vignesh RV et al (2020) Effect of shoulder features during friction spot extrusion welding of 2024-T3 to 6061T6 aluminium alloys. Arch Civ Mech Eng 20. https://doi.org/10. 1007/s43452-020-00086-2

2. Winiarski G, Gontarz A, Samołyk G (2019) Flange formation in aluminium alloy EN AW 6060 tubes by radial extrusion with the use of a limit ring. Arch Civ Mech Eng 19:1020-1028. https://doi. org/10.1016/j.acme.2019.05.006

3. Chen G, Chen M, Wang N, Sun J (2016) Hot forming process with synchronous cooling for AA2024 aluminum alloy and its application. Int J Adv Manuf Technol 86:133-139. https://doi. org/10.1007/s00170-015-8170-3

4. Umar MJ, Palaniappan PLK, Maran P, Pandiyarajan R (2021) Investigation and optimization of friction stir welding process parameters of stir cast AA6082/ZrO/BC composites. Mater Sci 38:715-730. https://doi.org/10.2478/msp-2020-0082

5. Gronostajski Z, Niechajowicz A, Polak S (2010) Prospects for the use of new-generation steels of the ahss type for collision energy absorbing components. Arch Metall Mater 55:221-230

6. Li X, Chang Y, Wang C et al (2017) Comparison of the hotstamped boron-alloyed steel and the warm-stamped medium-Mn steel on microstructure and mechanical properties. Mater Sci Eng A 679:240-248. https://doi.org/10.1016/j.msea.2016.10.045

7. Sadowski T, Nowicki M, Pietras D, Golewski P (2019) Gradual degradation of a thin-walled aluminum adhesive joint with omega cross section under bending. Int J Adhes Adhes 89:72-81. https:// doi.org/10.1016/j.ijadhadh.2018.11.011

8. Wojdat T, Kustroń P, Jaśkiewicz K et al (2019) Numerical modelling of welding of car body sheets made of selected aluminium alloys. Arch Metall Mater 64:1403-1409. https://doi.org/10. 24425/amm.2019.130107

9. Kubit A, Kluz R, Trzepieciński T et al (2018) Analysis of the mechanical properties and of micrographs of refill friction stir spot welded 7075-T6 aluminium sheets. Arch Civ Mech Eng 18:235-244. https://doi.org/10.1016/j.acme.2017.07.005

10. Krajewski P (2012) Stamping of age-hardenable aluminum alloy sheets. United States Pat US 2012/0186706 A1 002:354. https:// doi.org/10.1037/t24245-000

11. Argandoña ES, Galdos L, Ortubay R et al (2015) Room temperature forming of AA7075 aluminum alloys: W-temper process. Key Eng Mater 651-653:199-204. https://doi.org/10.4028/www. scientific.net/KEM.651-653.199

12. Mahabunphachai $S$, Koç $M$ (2010) Investigations on forming of aluminum 5052 and 6061 sheet alloys at warm temperatures. Mater Des 31:2422-2434. https://doi.org/10.1016/j.matdes.2009. 11.053

13. Wang H, Luo YB, Friedman P et al (2012) Warm forming behavior of high strength aluminum alloy AA7075. Trans Nonferrous Met Soc China (English Ed) 22:1-7. https://doi.org/10.1016/ S1003-6326(11)61131-X

14. Shen Z, Zhang L, Li P et al (2021) Dynamic failure mechanism of copper foil in laser dynamic flexible forming. Mater Sci 38:684692. https://doi.org/10.2478/msp-2020-0083

15. Kumar M, Poletti M, Degischer HP (2013) Precipitation kinetics in warm forming of AW-7020 alloy. Mater Sci Eng A 562:362 370. https://doi.org/10.1016/j.msea.2012.10.031 
16. Polak S, Kaczyński P, Gronostajski Z et al (2017) Warm forming of 7075 aluminum alloys. Procedia Eng 2399-2404

17. Deng L, Wang X, Jin J, Xia L (2017) Springback and hardness of aluminum alloy sheet part manufactured by warm forming process using non-isothermal dies. Procedia Eng 207:2388-2393. https:// doi.org/10.1016/j.proeng.2017.10.1013

18. Wang N, Ilinich A, Chen $M$ et al (2019) A comparison study on forming limit prediction methods for hot stamping of 7075 aluminum sheet. Int J Mech Sci 151:444-460. https://doi.org/10. 1016/j.ijmecsci.2018.12.002

19. Liu Z, Li L, Wang G et al (2020) Correction to: springback behaviors of extruded 6063 aluminum profile in subsequent multi-stage manufacturing processes. Int J Adv Manuf Technol 109:15-16. https://doi.org/10.1007/s00170-020-05694-z

20. Xiao W, Huang L, Li J et al (2019) Investigation of springback during electromagnetic-assisted bending of aluminium alloy sheet. Int J Adv Manuf Technol 105:375-394. https://doi.org/10.1007/ s00170-019-04161-8

21. Chen P, Lin ZQ, Chen GL, Muammer K (2006) Parametric analysis of warm forming of aluminum blanks with FEA and DOE. Trans Nonferrous Met Soc China (English Ed) 16:267-273. https://doi.org/10.1016/S1003-6326(06)60045-9

22. Foster A, Dean T, Lin J (2013) Process for forming aluminium alloy sheet components. Eur Pat WO 2010/032002 1:1-11

23. Mackenzie SD, Newkirk J (2001) Quench factor analysis for heat treatment optimization of 7XXX aluminum alloys. Proc 8th Semin IFHTSE, Dubrovnik, Croat 119

24. Mattos WS, Totten GE, Canale LCF (2016) Quenching of aluminum alloys. ASM Handbook, Vol 4E. Heat Treat Nonferrous Alloy 4E:148-178. https://doi.org/10.1520/MPC20160125

25. Xiao W-C, Wang B-Y, Kang Y et al (2017) Deep drawing of aluminum alloy 7075 using hot stamping. Rare Met 36:485-493. https://doi.org/10.1007/s12598-017-0919-4

26. $\mathrm{Hu}$ M, Bi N, Liu M et al (2020) Rapid sintering of TiB ceramics using $\mathrm{Co}$ as sintering aid under high pressure condition. Mater Sci 38:502-507. https://doi.org/10.2478/msp-2020-0050
27. Zhu L, Liu Z, Zhang Z (2019) Investigation on strengthening of 7075 aluminum alloy sheet in a new hot stamping process with pre-cooling. Int J Adv Manuf Technol 103:4739-4746. https://doi. org/10.1007/s00170-019-03890-0

28. Liu Y, Zhu Z, Wang Z et al (2018) Flow and friction behaviors of 6061 aluminum alloy at elevated temperatures and hot stamping of a B-pillar. Int J Adv Manuf Technol 96:4063-4083. https://doi. org/10.1007/s00170-018-1790-7

29. Liu Y, Zhu Z, Wang Z et al (2017) Formability and lubrication of a B-pillar in hot stamping with 6061 and 7075 aluminum alloy sheets. Procedia Eng 207:723-728. https://doi.org/10.1016/j. proeng.2017.10.819

30. Yildirim M, Özyürek D, Gürü M (2016) The effects of precipitate size on the hardness and wear behaviors of aged 7075 aluminum alloys produced by powder metallurgy route. Arab J Sci Eng 41:4273-4281. https://doi.org/10.1007/s13369-016-2078-6

31. Li Z, Xiong B, Zhang Y et al (2008) Investigation of microstructural evolution and mechanical properties during two-step ageing treatment at 115 and $160{ }^{\circ} \mathrm{C}$ in an $\mathrm{Al}-\mathrm{Zn}-\mathrm{Mg}-\mathrm{Cu}$ alloy prestretched thick plate. Mater Charact 59:278-282. https://doi.org/ 10.1016/j.matchar.2007.01.006

32. Stiller K, Warren PJ, Hansen V et al (1999) Investigation of precipitation in an $\mathrm{Al}-\mathrm{Zn}-\mathrm{Mg}$ alloy after two-step ageing treatment at 100 and $150{ }^{\circ} \mathrm{C}$. Mater Sci Eng A 270:55-63. https://doi.org/ 10.1016/S0921-5093(99)00231-2

33. Dehghani K, Ghorbani R, Soltanipoor AR (2015) Microstructural evolution and mechanical properties during the friction stir welding of 7075-O aluminum alloy. Int J Adv Manuf Technol 77:1671-1679. https://doi.org/10.1007/s00170-014-6574-0

Publisher's note Springer Nature remains neutral with regard to jurisdictional claims in published maps and institutional affiliations. 